\title{
EL INDIGENISMO EN CONSTRUCCIÓN. CABILDEO INTERAMERICANO E INVESTIGACIÓN DE CAMPO EN LOS INICIOS DEL INSTITUTO INDIGENISTA INTERAMERICANO (1940-1946)
}

\author{
Paula López Caballero \\ Universidad Nacional Autónoma de México
}

$\mathrm{E}_{\text {cido de la historia de los proyectos indigenistas en México: }}^{\text {ste artículo reconstruye y analiza un capítulo poco cono- }}$ la exploración económico-cultural de la zona oncocercosa de Chiapas, coordinada por Manuel Gamio, director del Instituto Indigenista Interamericano (en adelante III), en 1945. Se trata de la primera investigación de campo abanderada por el Instituto, cuya creación recién se había formalizado en $1942 .{ }^{1}$ Es también la primera que conjuga investigación de campo antropológica con un fin "práctico" (lo que más tarde se llamará "antropología aplicada”), orientada al diseño y mejora de políticas públicas. Por último, aunque rara vez es tomada en cuenta en las historias más clásicas del indigenismo oficial, esta exploración abrirá una

Fecha de recepción: 20 de noviembre de 2019

Fecha de aceptación: 10 de febrero de 2020

${ }^{1}$ Los proyectos que hasta entonces trataba de desarrollar el Instituto estaban orientados a la conservación y recolección de cultura material o a la redacción de investigaciones históricas, aun si en su convención se especificaban como sus funciones "iniciar, dirigir y coordinar investigaciones y encuestas científicas que tengan aplicación inmediata a la solución de los problemas indígenas". Convención sobre el III, Artículo IV, punto 3. 
serie de preguntas, de conceptos y de contradicciones que serán claves en el desarrollo posterior del Instituto Nacional Indigenista (INI, creado en 1948). ${ }^{2}$

En la primera sección de este artículo analizo el intrincado andar de este proyecto, desde que empezó a ser enunciado (1940) hasta su puesta en práctica (1945). Pretendo así acceder al funcionamiento práctico, interno y cotidiano del III, teniendo como base empírica la correspondencia, informes no publicados y prensa de dicho Instituto. ${ }^{3}$ ¿Con qué medios económicos, humanos, políticos, contaba el naciente instituto? ¿Qué retos enfrentaba para llevar a cabo su política? ¿Qué estrategias y qué negociaciones debió hacer tanto frente a otros expertos como entre sus propios colaboradores y sus distintas perspectivas?

Esta mirada a la faceta más institucional del proyecto se complementa, en la segunda sección, al detallar la expedición misma, haciendo uso de los reportes y correspondencia desde el campo, las bitácoras y diarios que he podido encontrar

2 La bibliografía al respecto es aún escasa. El llamado "proyecto oncocercosis” ha sido trabajado por Laura Giraudo quien, además de ser pionera en el estudio de los archivos del Instituto Indigenista Interamericano, recientemente presentó un trabajo intitulado “ ¿Patología indígena o enfermedad profesional? La oncocercosis en Oaxaca y Chiapas, 1920-1950” (INAH, Ciudad de México, 6 de septiembre de 2019). Además de los trabajos antropológicos publicados a raíz de esta exploración, tales como GAMIO, "Exploración económico-cultural [...]”, Montemayor, Los efectos de la onchocercosis; Pozas, "Los mames de la región oncocercosa [...]" y "El trabajo en las plantaciones [...]", breves menciones a dicha expedición se encuentran en una biografía reciente de Franz Blom redactada por Nielsen, Restless Blood, pp. 224-227; GudiÑo, Educación higiénica; y Hernández, Histories and Stories, 49, pp. 56-60.

3 El uso de fuentes primarias y el interés por las prácticas y las rutinas de las instituciones han permitido una revisión innovadora de la historia del indigenismo. Véase Dillingham, “Indigenismo Occupied”; Giraudo y Sánchez, La ambivalente historia; LEgARRETA, "Ingeniería social”; LEWIS, Rethinking Mexican Indigenismo; López Caballero, "Las políticas indigenistas” y "Anthropological Debates"; MuÑoz, Stand Up and Fight; RoBInet, "Hermanos de raza”; SARIEgo, El indigenismo en la Tarahumara; SchwarTzFrancisco, “Transforming the Tropics” y "Displacement, Development”. 
de los antropólogos que participaron en ella. La pluralidad de posturas, desacuerdos y desfases que pueden documentarse muestra que tampoco dentro del proyecto indigenista había consenso ni sobre la labor científica del antropólogo ni sobre la función práctica del indigenismo. Más aún, los desacuerdos internos muestran que la definición misma del sujeto a intervenir y las causas de sus problemas, lejos de ser una certeza consensuada, constituyeron un álgido punto de tensión. ¿Qué significaba en ese momento llevar a cabo un proyecto de acción pública con la etiqueta "indigenista"? ¿Cómo se construye progresivamente la legitimidad de dicho dispositivo de expertise y de intervención pública? ¿Qué sujetos sociales debían ser intervenidos y cómo se definirían sus problemas? De esta batalla de arenas múltiples emergerá cierta noción de "cultura" entendida como el marcador social que delimitaría tanto el perímetro de grupos distintivos -los indígenas- como la "utilidad" del antropólogo, único experto preparado para estudiarla y transformarla.

En conjunto, el presente análisis pretende demostrar, por un lado, el valor heurístico de analizar la vida institucional desde sus prácticas, generalmente más contradictorias y heterodoxas que las representaciones lisas y coherentes de las retóricas oficiales; en otras palabras, ir más allá de lo que Hansen y Stepputat llaman "la propia prosa del Estado". ${ }^{4}$ Y por otro, intento fracturar la narrativa más generalizada en la historiografía indigenista al mostrar que categorías e instituciones como "indigenismo", "antropología” e incluso "indígena" estaban aún en proceso de definición en 1940. En efecto, uno de los resultados de este examen es que la "política indigenista", aunque ha tendido a estudiarse y entenderse como un corpus claramente delimitado y fijado de una vez y para siempre, no existía como tal a principios de la década de 1940. Se trataba aun de un tipo de intervención

${ }^{4}$ Hansen y Stepputat, States of Imagination, p. 14. 
pública más bien experimental, sin perímetros claros, ni resultados evidentes. El estudio de este proyecto deja claro, asimismo, que el vínculo entre antropología e indigenismo -que con los años se volvió casi "natural"- no se había establecido aún. Es más, que la definición misma del trabajo antropológico estaba todavía en proceso de definición y de consolidación. Más complejo, tal vez, es que algo similar sucedía con el sujeto indígena, aquel que debía ser beneficiario de dicha política. En efecto, la documentación relativa al proyecto oncocercosis muestra que el mundo rural era, a mediados de la década de 1940, aún largamente desconocido, tanto para los "científicos sociales" como para el propio gobierno (por ejemplo, en la elaboración de mapas y censos). En este contexto saber quién era indígena, qué lo definía como tal, cuáles eran las causas de sus problemas y cómo solucionarlos no eran, en términos generales, verdades consensuadas sino campos de abierta disputa. En suma, mi argumento invierte la causalidad más generalizada en la historiografía sobre el indigenismo y sobre las relaciones entre los pueblos indígenas y el Estado-nación: que la diferencia cultural atribuida a los indígenas no es, al menos en este caso, la causa de la intervención gubernamental sino su consecuencia.

\section{Recuadro 1 \\ LA ONCOCERCOSIS, SINTOMATOLOGÍA E HISTORIA}

La oncocercosis (también onchocercosis) es una enfermedad parasitaria provocada por la Onchocerca volvulus. Se transmite por la picadura de moscas negras infectadas o mosquitos (Simulium spp.) que se crían en ríos rápidos y arroyos. En el cuerpo humano, los gusanos adultos producen larvas embrionarias (microfilarias) que migran a la piel, los ojos y otros órganos. Los síntomas más recurrentes de la enfermedad en su estado avanzado son la formación de nódulos subcutáneos y lesiones oculares que pueden producir discapacidad visual y ceguera permanente. 
A la fecha no existe cura o vacuna contra ella. Esta enfermedad fue detectada desde la década de 1910 en Guatemala. En México, la primera noticia oficial que se tuvo de este padecimiento en el territorio nacional fue en 1925. Al año siguiente, además del Soconusco en el estado de Chiapas, se confirmó que dicho mal estaba presente también en la Sierra Norte de Oaxaca. En 1931, se crea la Campaña contra el Mal del Pinto y la Oncocercosis. En 1935 la oncocercosis es considerada un asunto de interés federal. ${ }^{5}$ En 1938 el presidente Cárdenas autoriza la construcción de una clínica de especialidad dedicada al tratamiento de la oncocercosis (que entrará en funcionamiento en 1942) en Huixtla, Chiapas, donde desde 1929 existía un dispensario encargado de atender a enfermos de dicho padecimiento. ${ }^{6}$

EL MUNDO RURAL EN DISPUTA:

MÉDICOS Y ANTROPÓLOGOS EN LOS CORREDORES DE LA POLÍTICA NACIONAL Y LA POLÍTICA INTERAMERICANA

La llamada “enfermedad de la ceguera” aparecerá en la mira de los indigenistas por primera vez en el Congreso Indigenista Interamericano de Pátzcuaro (abril 1940). Tres ponencias abordarán este tema en la sección "Salubridad”: una, más etnológica, sobre las "creencias indígenas sobre la onchocercosis [...]", presentada por el antropólogo autodidacta Julio de la Fuente. Las otras dos, médicas: una presentada por el médico Luis Figueroa, en la cual explica las características de la enfermedad. La otra, por el entomólogo Alfonso Dampf, quien, a partir de estudios entre la población de Chiapas, sostenía la existencia

${ }^{5}$ Desde entonces, el gobierno de Cárdenas había solicitado apoyo financiero a la Rockefeller Foundation sin éxito, dado que dicha fundación "refused to participate in a disease control effort which did not have existing treatment and control measures, or one that might require social interventions". BIRN, "Wa(i)ves of Influence", p. 386.

6 Programa Nacional para la eliminación de la Oncocercosis, 2014. 
de un vínculo estrecho entre la enfermedad y lo que entonces aún se denominaba "raza", considerando a la oncocercosis como un "problema interamericano de los indígenas". 7 Tras el Congreso de Pátzcuaro, el director provisional del aún en ciernes Instituto Indigenista Interamericano, Carlos Girón Cerna, invitará a todos los participantes a publicar en la novel revista América Indígena, incluido el doctor Dampf. Éste recibirá, además, en pluma de Emil Sady, representante en el III de la Office of Indian Affairs de Estados Unidos, la seguridad de que "el Instituto promoverá por todos los medios a su alcance, el programa para controlar la incidencia y expansión de esta enfermedad". Y también le aclara: "he escrito a Washington sugiriendo que éste debe ser un proyecto en el que colaboren y ayuden financieramente. Espero que juntos podamos trabajar en montar pronto un proyecto definitivo". ${ }^{8}$ Esta ruta de trabajo abierta por Sady contrasta con los proyectos que hasta ese momento estaba tratando de desarrollar el Instituto, orientado -podría decirsehacia el pasado. Esto es, la historia prehispánica y la conservación de cultura material. Así, la oncocercosis abría una pequeña oportunidad para atender un problema social contemporáneo que, a decir de Dampf, era particularmente amenazante para los indígenas. Faltaba que el problema tuviera también una dimensión interamericana, la cual aparecerá por otra vía inesperada.

Unos meses después, en noviembre de 1941, en un esfuerzo por consolidar los vínculos entre indigenismo nacional e indigenismo interamericano, Sady visitará Guatemala, en una gira organizada por Carlos Girón, originario de dicho país. Este último

\footnotetext{
7 En la ponencia de Pátzcuaro este vínculo sólo se sugiere en el título, pero en un artículo posterior Dampf afirma que "La raza blanca posee aparentemente inmunidad parcial contra la oncocercosis. [Por ello] la oncocercosis merece $[\ldots]$ en interés de las razas indígenas, la más seria atención”. DAMPF, "La carretera panamericana”, pp. 756, 757.

8 AHPUIC, III, SAE, CD México en el archivo histórico, Desde Blom hasta Dampf, “Carta de Sady a Dampf”, 19 de julio de 1941.
} 
concerta una entrevista entre Sady y el director general de Sanidad Pública, Carlos Esteves, a quien Sady solicita un informe sobre la oncocercosis. En dicho informe, el doctor Esteves expone la intención de "interesar a alguna fundación filantrópica para sufragar los gastos de investigación”, pues es imperante establecer una comisión de investigación médica-biológica sobre la filaria. ${ }^{9}$ Y concluye abonando abiertamente al espíritu interamericano del Instituto: "Creemos que si una institución benéfica norteamericana patrocina dichas investigaciones deben ser hechas en colaboración con los médicos mexicanos, guatemaltecos [...] con el fin de favorecer en un ideal panamericanista [a estos] dos países" ${ }^{10}$ A ojos de este funcionario, entonces, el III se parecía más a una plataforma para acceder a los fondos de las fundaciones norteamericanas que a un organismo con un proyecto inteligible, encargado de liderar cierto tipo de acción pública y con un ámbito de intervención definido. Ello muestra a qué grado el área de expertise y el perímetro de intervención del indigenismo eran aún una tarea en construcción.

Es posible, por otro lado, que la declaración de un problema común a México y Guatemala cumpliera con las expectativas de la vocación interamericana del Instituto, aún en ciernes. Ello explica, quizá, que tras anunciar a Dampf en enero que su ponencia del Congreso de Pátzcuaro se publicaría en la revista del Instituto, un mes después el propio Girón la rechace por "caduca": "como han pasado ya dos años desde la celebración de dicho Congreso, y el programa [contra la oncocercosis] está ya mucho más adelantado, nos hemos visto privados del placer de publicar su artículo [...]”. ${ }^{11}$ El entomólogo no volverá a colaborar con el

\footnotetext{
9 AHPUIC, III, SDG, 24, Dr. Carlos Esteves, Marroquín, Bernard y Herrera, "Informe sobre el problema de la filaria en Guatemala", 1941, pp. 1, 2.

${ }^{10}$ AHPUIC, III, SDG, 24, Dr. Carlos Esteves, Marroquín, Bernard y Herrera, "Informe sobre el problema de la filaria en Guatemala", 1941, pp. 5, 6. 11 AHPUIC, III, SAE, CD México en el archivo histórico, Desde Blom hasta Dampf, “Carta de Girón a Dampf”, 7 de febrero de 1942.
} 
Instituto. En cambio, el proyecto tripartito con Guatemala va haciendo su camino: una vez definido el problema y el territorio, el "proyecto oncocercosis" se lanzará a los laberintos de la diplomacia interamericana en busca de financiamiento. Esta etapa puede entenderse, a la distancia, como un periodo de lucha para determinar qué expertos son los más indicados para atender el problema, lo cual a su vez suponía, efectivamente, tener la voz legítima para definir dicho problema. El reto para el III consistía en disputar un terreno -el mundo rural y sus problemas- que empezaba a estar dominado por los médicos. ${ }^{12}$ Como veremos, el balance global de esta batalla será ambiguo. Si a lo largo de este proceso, el indigenismo empezará a crear un nicho legible y visible, el lugar que este ocupará frente a la medicina y los médicos, tanto en el plano nacional como en el internacional, seguirá siendo muy marginal.

Un primer indicio de esta lucha por fondos y por autoridad aparece al poco tiempo. En mayo de 1942, desde Washington la oficina de John Collier, comisionado de la Oficina de Asuntos Indígenas en Estados Unidos y principal aliado del III, comunica a Girón Cerna que ha discutido el proyecto con la Oficina Sanitaria Panamericana (en adelante OsP), cuyo director "siente que el Proyecto podría ser mejor administrado por ellos”. Es más, sugieren que, a pesar de ser una iniciativa del III, este instituto solicite que la osp lleve a cabo un proyecto para estudiar la enfermedad, en vista de "la larga experiencia que [la osP] tiene en el campo médico" y de la cual el III carece. ${ }^{13}$ En dicha redacción, la participación del III se justificó afirmando que "Más de cuarenta mil indígenas en México y Guatemala están afectados por la

\footnotetext{
12 Agostoni, "Médicos rurales"; y Meza-Huacuja, "De la Universidad al campo", examinan las políticas que, desde la década de 1930, estaban dirigidas explícitamente a llevar a los médicos, hasta entonces eminentemente urbanos, al campo.

13 AHPUIC, III, SAE, CD de datos Correspondencia de John Collier, "Carta de Ch. Collier a Girón”, 20 de marzo de 1942.
} 
oncocercosis [y] sus creencias sobre la enfermedad y el miedo a la cirugía moderna para extraer los quistes [...] crean problemas particulares para su tratamiento". ${ }^{14}$

Semanas después, el Consejo Directivo del III retoma puntualmente la redacción enviada desde Washington y la adopta como una de las "resoluciones" del instituto. ${ }^{15}$ Con ello, el proyecto pasaba a manos de la osp, dejando al III con un papel más bien indefinido de "copatrocinador", sin objetivos ni acciones claras. Esta primera "batalla” -perdida para el III - hace explícita la falta de visibilidad de lo que apenas empieza a llamarse "política indigenista”, a no ser por la especificidad -más presupuesta que demostrada, como se verá en la segunda parte de este artículo-de los llamados grupos indígenas y sus creencias.

Ya instalado como director del III en ese mismo mes de mayo, Manuel Gamio propone organizar una reunión preparatoria en la ciudad de México con las partes interesadas para elaborar un proyecto definitivo y un presupuesto que eventualmente pudiera ser sometido a la Oficina para la Cooperación de Asuntos Interamericanos (OCAI). Dirige esta propuesta a Arístides Moll, secretario de la osp, donde además reconoce y reafirma el papel del Instituto como "copatrocinador [...] y coordinador de las agencias participantes” en el proyecto. ${ }^{16}$ Notifica igualmente esa iniciativa a Collier en una carta más confidencial, donde además expresa su preocupación por el papel del III: “Confidencialmente, creo que debemos ser cuidadosos de que nuestro Instituto no sea expulsado del papel prominente que ha ocupado en fomentar un estudio colaborativo sobre esa enfermedad por los gobiernos

14 AHPUIC, III, SDG, 69, Proyecto sobre onchocercosis, 1941-1945 (2 legajos), "Status of oncocercosis Project”, 21 de marzo de 1942. Énfasis añadido. 15 AHPUIC, III, SDG, 69, Proyecto sobre onchocercosis, 1941-1945 (2 legs.), "Resoluciones del consejo directivo sobre un estudio de la oncocercosis", 6 de mayo de 1942, pp. 3, 4.

16 AHPUIC, III, SDG, 69, Proyecto sobre onchocercosis, 1941-1945 (2 legs.), carta de Gamio a Moll, 31 de julio de 1942. 
concernidos. Para ello, creo que debemos asegurar el apoyo material necesario $[\ldots]]^{\prime}{ }^{17}$

La reunión, convocada tanto por la osP como por el III, tendrá lugar en la ciudad de México del 21 al 30 de enero de 1943 y la prensa redactará numerosos artículos desde los días previos al acto y durante la Conferencia misma. ${ }^{18}$ En ellos, la dificultad de hacer visible la función del iII se hace patente de nuevo: salvo excepción, la mayoría se concentran en el aspecto médico del problema y en las instituciones federales encargadas de atenderlo. ${ }^{19}$ Una de esas notas reporta que Gamio, en nombre del Instituto, invita a todos los médicos a una comida [...] a las grutas de Teotihuacán (¡!) donde además ofrece una visita por el sitio arqueológico que tan bien conocía. ${ }^{20}$ La paradoja de este acto no carece de significado: por un lado, Gamio volvía a situarse como experto del pasado indígena, no como un líder que pudiera aportar soluciones prácticas a las realidades presentes. Por otro, el "indígena” conocido y visible para estos expertos

17 AHPUIC, III, SDG, 69, Proyecto sobre onchocercosis, 1941-1945 (2 legs.), carta de Gamio a Collier, 31 de julio de 1942.

18 "Conferencia para la campaña contra la onchocercosis", El Nacional (12 ene. 1943); "Contra el mosquito de la oncocercosis", El Universal (14 ene. 1943); "Altos funcionarios sanitarios panamericanos llegaron a México", El Nacional (20 ene. 1943); "Plática preliminar sobre onchocercosis", El Universal (21 ene. 1943); "Se inició ayer la conferencia de la onchocercosis", $E l$ Universal (22 ene. 1943); "Acuerdos de la Junta de la Onchocercosis", Excelsior (24 ene. 1943); "El plan concreto para la campaña a la onchocercosis", $E l$ Nacional (25 ene. 1943).

19 Participaron el doctor Carlos Esteves y el doctor. J. A. Bennard, por el gobierno de Guatemala. Por la osP, John C. Murdock. Y por el gobierno mexicano: Víctor Fernández Manero, jefe del Departamento de Salubridad Pública, Salvador González Herrejón, jefe de la Oficina de la Campaña contra el Paludismo, la Oncocercosis y otras Parasitosis; Miguel Bustamante, director del Instituto de Enfermedades Tropicales; Manuel Martínez Báez, director general de Epidemiología del mismo Departamento, y Luis Figueroa, jefe de la campaña contra la oncocercosis en Chiapas, del Departamento de Salubridad. 20 "Agasajo a los médicos de la onchocercosis", Excelsior (28 ene. 1943). 
era aquel del glorioso pasado de las pirámides y no el habitante coetáneo enfrentado a problemas sociales actuales. El 31 de ese mes se da por clausurada la que ya se llama Conferencia Interamericana de Onchocercosis y se emite un acta final que propone aumentar el número de brigadas sanitarias e intensificar la investigación. ${ }^{21}$ Dicha investigación debía incluir un "estudio de medio ambiente y de las características de la población”, así como el "estudio de los grupos sociales que habitan las zonas de endemia oncocercosa". ${ }^{22}$ El papel del III en el proyecto quedaba así asegurado.

En mayo de ese mismo año (1943), durante la sesión extraordinaria del Consejo Directivo del III, Gamio informa que el "Proyecto para combatir la oncocercosis" fue presentado a la ocar la cual, según informó el doctor Fernández Manero (jefe del Departamento de Salubridad Pública) invertirá en "la campaña contra la onchocercosis [una suma que] excederá de medio millón de dólares, comenzándose los trabajos el pxmo. mes de julio". ${ }^{23}$ En realidad la OCAI solo otorga 100000 dólares al proyecto global ese mismo año, aunque la campaña médica no se pondrá en marcha sino hasta 1944 y la investigación "económico-cultural”, como la llamará Gamio, se retrasará hasta enero de $1945 .{ }^{24}$ De ese monto, la investigación dirigida por Gamio contó, finalmente, con tan solo 10000 dólares de la OCAI, apenas $10 \%$ del total invertido. ${ }^{25}$

${ }^{21}$ En su ponencia de 1940, Dampf calculaba que existían 10 brigadas en Chiapas pero que harían falta 200 médicos activos en el campo para empezar a cambiar la situación.

22 AHPUIC, III, SDG, 69, Proyecto sobre oncocercosis, 1941-1945 (2 legs.), "Acta Final de la conferencia preliminar de la oncocercosis", p. 8.

23 AHPUIC, III, SDG, "Sesión extraordinaria del Consejo Directivo del III", 7 de mayo de 1943, pp. 6, 7 .

${ }^{24}$ AHPUIC, III, SI, 4, "Informe sobre el progreso de las investigaciones de la oncocercosis, diciembre de 1943-enero de 1945”, pp. 15-16.

25 AHPUIC, III, SAE Centro de información acervos especiales, CD Datos, Correspondencia 1940, "Informe sobre las funciones y actividades del 
Del total del personal contratado para el Proyecto médicosanitario (alrededor de 65 personas), 12 están comisionadas a la investigación "económica-cultural" y solo cinco son antropólogos (véase la tabla 1). Cada investigador debía enviar informes mensuales y un reporte final debía entregarse al gobernador del estado de Chiapas en una reunión de todos los comisionados en junio, cuando todas las investigaciones debían culminar. Esta reunión finalmente no ocurrirá y en su lugar Gamio publica en América Indígena un informe, suerte de "versión oficial" de la expedición, que el autor presenta como una "síntesis, sencillamente formulada [en la que procura] agrupar, coordinar y complementar las principales observaciones y conclusiones de dichos estudios". ${ }^{26}$

Publicado en 1946, es la referencia habitual al hablar de este proyecto. ${ }^{27}$ Consta de 47 páginas en las que abarca desde el medio geográfico, la flora y fauna del Soconusco, los antecedentes prehispánicos y coloniales de la población en dicha zona, y la sección más amplia está dedicada a "la población contemporánea”. ${ }^{28}$ En esta última sección aclara que hay 17 municipios infectados, todos ellos dedicados al cultivo intensivo del café, en cuyas plantaciones se contrata en su gran mayoría a trabajadores "del municipio de Chamula [...] y de las vertientes occidentales del volcán Tacaná”. En cuanto a la situación social en la región, Gamio reconoce que "los prejuicios [...] de carácter racial [...] felizmente no existen en la región o sus efectos son insignificantes, como lo demuestra el

Instituto Indigenista Interamericano durante el sexenio comprendido desde 1942 en que fue legalmente organizado hasta 1948". Véase también el anexo I. ${ }^{26}$ Gamio, "Exploración económico-cultural", p. 202.

27 Por ejemplo, Téllez Ortega, "La época de oro”, p. 295; Medina, "Ricardo Pozas en la trama", pp. 51,52; VÁzQuez, "Cafeticultura e historia social", p. 133.

${ }_{28}$ Sobre la situación agraria en el Soconusco véase Morales y Rivera, "De peones a ejidatarios". 
abundante mestizaje ahí existente". ${ }^{29}$ Afirmación que no deja de sorprender dadas las tensas relaciones sociales que caracterizan la región y que los propios actores definían como "raciales". El verdadero problema, dice el antropólogo, es "la pobre situación económica [y sobre todo] el inferior nivel cultural que caracterizan a la mayor parte de los habitantes". Aunque en el fondo la cuestión económica no es central, dado que "los hábitos culturales anacrónicos gravitan sobre las espaldas de [pobres y de quienes poseen medios económicos], como pesada losa, sin que se aperciban de ello". ${ }^{30}$ Dicho nivel cultural puede ser claramente aprehendido al establecer una tipología de personas y grupos, según si predominan las "características culturales de los tipos autóctono [...] occidental y [...] mixto". ${ }^{31}$ De ahí que la solución no sea "una campaña sistemática contra todas las características de esos grupos retrasados”. Más bien, el objetivo de dicho informe, según su autor, era

[...] sugerir [...] medidas prácticas para extirpar, reformar o substituir aquellas de las características materiales y abstractas de vida que por ser retrasadas, ineficaces o perjudiciales, obstaculizan el desarrollo biológico y cultural de la población oncocercosa, aconsejando en cambio la conservación y el estímulo de valiosas características autóctonas que en ella se observan. ${ }^{32}$

29 En este caso, me parece que el uso que hace Gamio de "mestizaje” refiere al sentido más literal de mezcla y no al proyecto ideológico nacionalista llamado "ideología del mestizaje". Con dicho argumento, Gamio parece olvidar que los prejuicios ocurren a pesar de-o incluso debido a-la intimidad entre grupos sociales definidos o percibidos como diferentes.

30 Gamio, "Exploración económico-cultural”, p. 229.

31 Gamio, "Exploración económico-cultural”, pp. 220, 221, 227.

32 Gamio, "Exploración económico-cultural", p. 202. Este programa de investigación y de transformación ya había sido desarrollado por Gamio en tres artículos publicados en América Indígena. Gamio, "Consideraciones"; "Las características culturales"; "Calificación de características". 
Además de definir el problema (la cultura) y sus soluciones, vale retener cuatro ideas transversales del informe preparado por Gamio. En primer lugar, el autor habla de manera genérica de toda una región (la "zona oncocercosa"), sin matices ni distinciones internas y que corresponde, grosso modo, al Soconusco. En segundo lugar, en este texto Gamio evita toda crítica a la acción gubernamental, la cual aparece retratada bajo su mejor ángulo, o al menos se detecta un esfuerzo por presentarla así. ${ }^{33}$ En tercer lugar, el eje principal de su argumento es la necesidad de una transformación a nivel cultural: "tampoco serán bastantes por sí mismas la mejoría exclusivamente económica y la implantación de un crédito [...] si paralelamente no se les hace objeto de una culturización inteligente que permita sustituir, reformar o desterrar ciertas anacrónicas e ineficaces características culturales $[\ldots]$ ". ${ }^{34}$ Pero lo más notable y sorprendente de esta síntesis es que -como mostraré en el apartado siguiente- tanto la información "dura" como el marco analítico "cultural" con el que la presenta no coinciden ni retoman ni se inspiran en los reportes, bitácoras y cuestionarios que fue recibiendo de sus comisionados en la zona ( $(!)$.

$\mathrm{Al}$ reconstruir los vericuetos políticos y administrativos que recorre el Proyecto Oncocercosis, se constata que la "política indigenista" no existía en tanto mecanismo de intervención con especificidad propia respecto de otros ámbitos de expertise dedicados a transformar el mundo rural. Sus aportes y sus métodos no eran evidentes para actores como los médicos -tanto

33 Por ejemplo, sobre las técnicas de roza y quema que entonces dominaban la agricultura local Gamio apunta: "se nos comunica de Chiapas que el Gobierno del Estado ha vendido a los campesinos mil arados al bajo precio de quince pesos por unidad". Sin embargo, Gamio debe matizar de inmediato esta "buena noticia" al precisar que "ignoramos si alguno de estos arados está destinados a la región oncocercosa [...]”. Gamio, "Exploración económico-cultural”, p. 211. Otro ejemplo similar al hablar de las brigadas sanitarias en GAMIO, "Exploración económico-cultural”, p. 225.

${ }^{34}$ Gamio, “Exploración económico-cultural”, p. 243. Énfasis añadido. 
en el plano nacional como en el interamericano- quienes, por lo demás, tenían relativamente poco tiempo de haber empezado a ocupar el territorio rural y a ser considerados expertos en su transformación sin contar que, posiblemente, tenían sus propias batallas dentro de su propia área de conocimiento. Los mínimos presupuestos con los que el III contó para este proyecto, su marginal visibilidad en la prensa y los acomodos que debieron hacer frente a otras instancias (por ejemplo, la OsP y la OCAI), confirman esta relativa ilegibilidad del proyecto indigenista. En efecto, aun recurriendo a la escala internacional, el reto para una política explícitamente indigenista en proceso de fabricación era cómo demostrar una autoridad y un savoir-faire específico.

El recurso que Gamio movilizó fue, como se vio, justificar la participación del III sobre la base de las dificultades "peculiares" que conllevaba el trabajo médico-sanitario en regiones mayoritariamente indígenas. De ahí que el reto de Gamio fuera triple: mostrar que la población afectada era mayoritariamente "indígena", que esta forma de identificación suponía necesariamente una alteridad radical, razón por la cual los antropólogos eran quienes tenían las herramientas idóneas para entenderlos y eventualmente transformarlos. Éstas consistían, sobre todo, en la tipificación de las "características culturales" de los distintos grupos sociales para definirlos (autóctonos, occidentales o mixtos) y, eventualmente, elegir cuáles de las características más primitivas debían ser transformadas para su mejoría. Ahora bien, ¿los investigadores en el campo compartían esta metodología de investigación sobre las "características culturales"?, ¿qué papel juegan en la explicación de los problemas estudiados?, ¿a ras del campo, la cultura aparecía tan determinante de la situación socioeconómica de la región y, por lo tanto, de las condiciones de propagación de la enfermedad?, ¿coincidían los antropólogos al momento de definir el sujeto que había que intervenir, el problema que lo aquejaba y el papel del antropólogo en ello? 


\section{EL TRABAJO DE CAMPO ANTROPOLÓGICO EN LA "EXPLORACIÓN ECONÓMICO-CULTURAL"}

A la versión "fría" y lisa presentada por Gamio en su informe es posible oponer una pluralidad de testimonios "calientes", diversos, relativamente desordenados, que expresan vivencias y encuentros más personales y directos con todo tipo de actores, desde jornaleros, administradores de fincas, representantes gubernamentales, médicos, maestros rurales, etc. Estas evidencias permiten develar una realidad-siempre mediada por la pluma de los investigadores- más compleja y caótica que la esbozada por Gamio. Y, sobre todo, el material reunido durante la ejecución práctica del proyecto cuestiona abiertamente las conclusiones presentadas por Gamio en ese informe, especialmente en lo relativo a los dos polos estructurantes del indigenismo: la dimensión indígena del problema y el papel del Estado como agente transformador de la cultura de dichos grupos.

Con fines expositivos, agrupé estos testimonios en tres subsecciones. Primero presento lo que se alcanza a saber sobre la logística misma de la expedición tal y como fue concebida por Gamio, así como las condiciones materiales de dicha expedición. Un segundo apartado detalla la información que estos investigadores de campo reúnen sobre la oncocercosis misma. En tercer lugar, me detengo en el papel que juegan los antropólogos más allá de las directivas de M. Gamio.

\section{Organizar una expedición, “... para obtener el conocimiento satisfactorio del desarrollo de estos indigenas..."}

El 7 de enero de 1945, en la pequeña ciudad de Huixtla, Chiapas, situada en la estrecha franja que corre entre la costa pacífica y la Sierra Madre Occidental, se reúnen en la clínica de especialidad dedicada al tratamiento de la oncocercosis todos 
los miembros de la expedición económico-cultural coordinada por el Instituto Indigenista Interamericano para una reunión preparatoria. Además de los comisionados, se encuentran M. Gamio y Juan Comas, en tanto que secretario del III, así como los médicos del centro: Luis Figueroa, Roberto Nettel, director de la clínica, y los representantes de la osp, Frederic Bartter y Marion T. Robbins.

\section{Tabla 1}

DISTRIBUCIÓN DEL TRABAJO EN LA EXPEDICIÓN ECONÓMICO CULTURAL...

\begin{tabular}{ll}
\hline Nombre & Misión \\
\hline $\begin{array}{l}\text { Felipe Montemayor, antropólogo } \\
\text { físico }\end{array}$ & $\begin{array}{l}\text { Investigación sobre las características } \\
\text { fisiológicas de los pacientes en la clínica } \\
\text { de Huixtla. }\end{array}$ \\
$\begin{array}{l}\text { Carlos Terrazas Vega y Héctor } \\
\text { Rodríguez, ingenieros agrónomos }\end{array}$ & $\begin{array}{l}\text { Lanaducción agropecuaria y } \\
\text { en las fincas y la situación agraria del } \\
\text { entonces Distrito del Soconusco. }\end{array}$ \\
Frederick Mullerried, geólogo & $\begin{array}{l}\text { Tipos de suelo, los minerales } \\
\text { explotables, las zonas geológicas. }\end{array}$ \\
$\begin{array}{l}\text { Eizi Matuda, naturalista y } \\
\text { botánico }\end{array}$ & $\begin{array}{l}\text { Flora y fauna de la región, para mejorar } \\
\text { su explotación e introducir cultivos } \\
\text { provechosos para la zona. }\end{array}$ \\
$\begin{array}{l}\text { Arturo Monzón, etnólogo } \\
\text { Ricardo Pozas y su esposa Isabel }\end{array}$ & $\begin{array}{l}\text { Dos pueblos indígenas: Acacoyahua } \\
\text { y Chamula }\end{array}$ \\
Horcasitas, etnólogos & Los ejidos del Distrito del Soconusco
\end{tabular}

35 Éste comprendía 14 municipios: Tapachula, Tuxtla Chico, Huehuetán, Cacahoatán, Unión Juárez, Frontera Hidalgo, Mazatán, Metapa, Acapetahua, Escuintla, Huixtla, Pueblo Nuevo Comaltitlán, Suchiate y Tuzantán.

${ }^{36} \mathrm{Su}$ expediente no está en el AHPUIC. 
Tabla 1

DISTRIBUCIÓN DEL TRABAJO (concluye)

\begin{tabular}{ll}
\hline Nombre & Misión \\
\hline $\begin{array}{l}\text { Frans Blom y Gertrude Duby, } \\
\text { antropólogos autodidactas }\end{array}$ & $\begin{array}{l}\text { Las rutas migratorias de los } \\
\text { trabajadores en las fincas y de la } \\
\text { oncocercosis misma en los estados de } \\
\text { Chiapas y Oaxaca, acompañados del } \\
\text { especialista en simúlidos, doctor José } \\
\text { Parra. }\end{array}$ \\
\hline
\end{tabular}

Elaborada por la autora.

En dicha reunión Gamio explica las misiones atribuidas a cada miembro de su equipo. Igualmente, entrega un "Programa de investigación" en donde su perspectiva sobre las "características culturales" y la necesidad de modificar algunas de ellas quedan claramente expuestas. ${ }^{37}$ La labor de los etnólogos consiste, según este documento, en determinar "el carácter eficiente, deficiente o perjudicial de habitación, vestido, alimentación [...] y en general todos los artículos que emplean o consumen, a fin de mejorarlos cuando esto sea posible o sustituirlos por otros más útiles $[\ldots]$.. ${ }^{38}$ En cuanto a la logística y los fondos, esa misma tarde se les entregan a cada expedicionario las cartas oficiales del III, del gobernador y del jefe de la zona militar fronteriza, así como un primer pago para sufragar viáticos y lo que en la contabilidad llaman "gratificación mensual" ${ }^{39}$

37 AHNB, 2, 38,007, Manuel Gamio, "Programa sintético para investigar las características de desarrollo económico cultural que existen entre los indígenas de las zonas oncocercosas de Guatemala y Chiapas, Méx., y deducir los medios que hay que implantar para mejorarlas", s. f.

38 AHNB, 2, 38,007, Gamio, Manuel "Programa sintético", s. f, p. 3.

39 Véase anexo I Gastos por investigador, elaborado a partir de AHSSA, SSA, SubSyA, 5, 17, 1945-49, fs. 183. Dado que la mayoría de ellos estaban 
Imagen 1

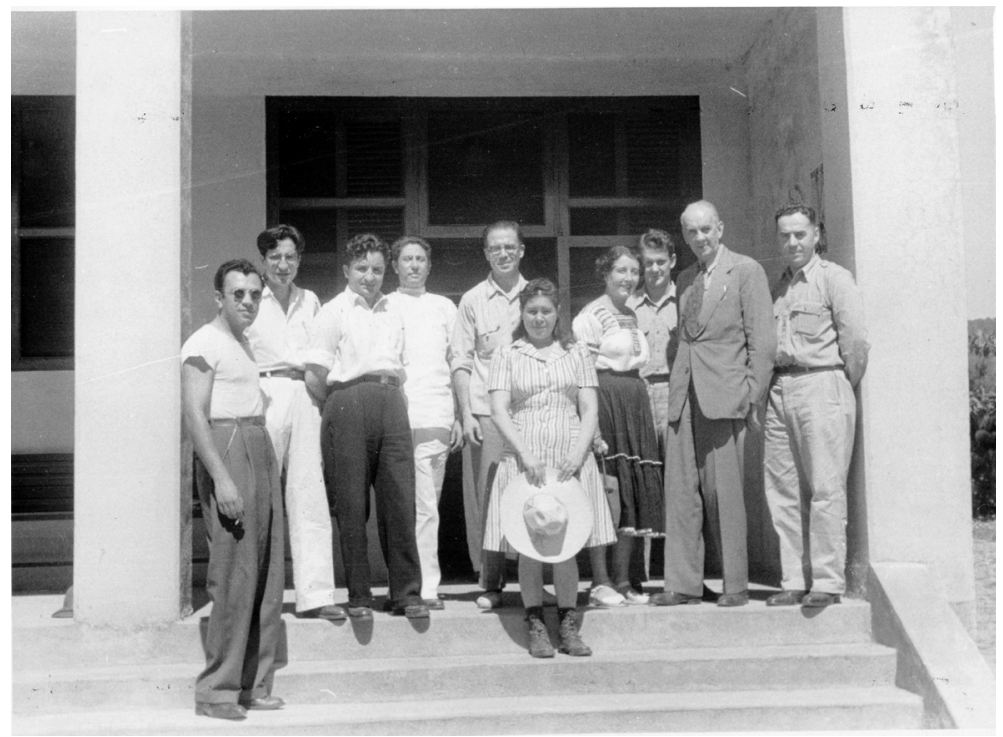

Miembros de la expedición económica-cultural en Huixtla.

De izquierda a derecha: abajo, Arturo Monzón, atrás Felipe Montemayor, Ricardo Pozas, un enfermero de la clínica, Isabel Horcasitas, Juan Comas,

Gertrude Duby, G. Donovan, Manuel Gamio y F. Bartter.

Instituto de Investigaciones Antropológicas, UNAM, Biblioteca "Juan Comas”, Archivo histórico “Alfonso Caso”, Fondo Juan Comas, Foto 257.

A lo largo de los meses siguientes, cada equipo o cada investigador le envía a Gamio un reporte mensual de actividades. Asimismo, todos mantuvieron una intensa correspondencia con el director del III, en la cual el problema que sobresale es la cuestión financiera. Por ejemplo, el antropólogo Arturo

comisionados por sus propias instituciones, no se les pagaba un salario; de ello depende la diferencia salarial. Este anexo permite constatar también que la mayoría del financiamiento de la osp al III se fue en viáticos y salarios (poco más de $50 \%$ ). 
Monzón le escribe a Gamio a menos de un mes de iniciada la expedición pidiéndole ayuda pues el doctor Figueroa no ha remitido sus fondos correspondientes al mes de febrero y él se encuentra con su familia haciendo la investigación. A lo cual Comas (en nombre de Gamio) explica que no está en sus manos pagarle "ya que toda la contabilidad está en Huixtla" a petición de la osp, que decidió depositar allá los fondos "para que el Dr. Luis Figueroa sea quien abone las cantidades presupuestadas". ${ }^{40}$ Poco después, a finales de febrero el mismo Figueroa dirige un oficio a todos los investigadores explicando la organización contable del proyecto: la ops ha informado que "solo ministrará en forma anticipada [...] la gratificación y viáticos del primer mes [y] los gastos que demande [cada] comisión [...] los cubrirá [...] al recibo de la comprobación respectiva". ${ }^{41}$ No es difícil imaginar la dificultad que suponía, en ese contexto, cumplir con tal requisito administrativo. Es lo que manifiesta F. Blom en una misiva dirigida directamente al representante de la osP, F. Bartter: "Esto puede que funcione muy bien para quienes están permanentemente en un solo lugar o que no deben seguir los caminos de terracería, pero no debería aplicarse a nuestro grupo. No podemos saber exactamente y en cualquier momento dónde será nuestra siguiente parada". ${ }^{42}$ Además de la dificultad para enviar los formularios y comprobantes, solicitar recibos por alimento para animales de carga, comida para los expedicionarios, hospedaje, etc., en pueblos, aislados, en muchos casos con un alto grado de analfabetismo e incluso a veces sin dinero circulante, resultaba

40 AHPUIC, III, SDG, 66, Correspondencia Arturo Monzón, "Carta de Monzón a Comas”, 5 de febrero de 1945, y “Carta de Comas a Monzón”, 10 de febrero de 1945.

${ }^{41}$ AHPUIC, III, SDG, 66, Correspondencia Frans Blom, "Carta de Figueroa a Blom", 27 de febrero de 1945.

${ }^{42}$ Mi traducción. AHPUIC, III, SDG, Correspondencia Frans Blom, Carta de Blom a Bartter, 9 de marzo de 1945. 
una proeza, si no un absurdo. ${ }^{43}$ Finalmente, en vista de las dificultades para comprobar gastos, se decide que el III adelantará los fondos a sus investigadores en espera de que la osP reembolse cuando se comprueben los gastos. La consecuencia de esta decisión terminará siendo perjudicial para el III pues muchos de esos gastos no podrán finalmente ser comprobados. Así, no solo este Instituto contó con fondos muy reducidos, que además no controlaba, sino que, en muchos casos, terminó cubriendo más gastos de los previstos en vista de los requisitos administrativos impuestos por la OsP.

La enfermedad de la ceguera:

"... el enemigo público número uno..."

A pesar de las limitantes constantes a las que se enfrentan los investigadores en el campo, la cantidad de información que se logra reunir no es nada despreciable, de ahí que sea aún más sorprendente (y significativa) la ignorancia de Gamio respecto de todo este material. Además de los reportes mensuales de Pozas, Monzón y Chapman (estos últimos extraviados), el equipo de Blom y Duby produjo por lo menos 26 cuestionarios correspondientes a las distintas localidades visitadas (véanse la imagen 2 y el anexo 2) y notas misceláneas referentes a 32 localidades. Este equipo elaboró también un informe sobre la relación entre el trabajo en las fincas y la propagación de la enfermedad, el proceso de enganche de trabajadores en Los Altos, así como una bitácora del viaje de Blom, otra redactada por Duby, gran cantidad de mapas y de bocetos señalando altitudes

\footnotetext{
43 A pesar de ello, contamos con una hoja escrita a mano intitulada "Gastos don José [Parra]” en donde Blom enlista los gastos para animales y para él en cada pueblo y da una idea de los costos de viaje: "Amatenango comida 3.55, maíz 0.5; Nuevo Amatenango, comida 4.00, maíz, 0.5; [...] Comalapa, comida 3.60, maíz, 0.5”, etc. AHNB, 2, 38,007.
} 
y distancias entre localidades, y una suma considerable de notas sueltas sobre poblados, paisajes, datos de informantes, listas de fincas cafeteras infectadas y fincas no contaminadas, entre muchos otros.

Entre ese cúmulo de papeles y textos "en crudo", se encuentran, por ejemplo, los estudios que Monzón realizó en dos fincas: La Esperanza, la más grande y productiva de la zona; y Europa La Bella, la más infectada y menos eficiente de la zona. Lejos de reportar sobre las características culturales de sus interlocutores, sus informes contienen censos y datos sobre la productividad, los salarios y las condiciones de trabajo. ${ }^{44}$ En la finca Europa la Bella, donde el cuadro es mucho más dramático, se incluye además un diagnóstico de las condiciones higiénicas y socioeconómicas de los trabajadores. Sobre lo primero, se señala su total deficiencia: no hay tomas de agua, lo cual hace que ésta se acumule favoreciendo el desarrollo del mosquito transmisor de la oncocercosis; las brigadas no visitan la finca con la frecuencia requerida y los servicios médicos son prácticamente inexistentes. En cuanto a las condiciones laborales, los salarios son muy bajos, los productos de primera necesidad son vendidos por comerciantes libres quienes abusan con precios exorbitantes y, al pagarse los salarios mensualmente, los trabajadores deben endeudarse continuamente. ${ }^{45} \mathrm{La}$ situación general de explotación que domina en las fincas se hace explícita en la conversación que Monzón reporta con el administrador, quien afirma: “Alguien tenía que decir estas cosas primero, y le tocó a usted'”, tras lo cual le advierte al antropólogo sobre "la oposición y la campaña

${ }^{44}$ AHPUIC, III, SDG, 66, Correspondencia Arturo Monzón, "Informe mensual correspondiente a marzo", 1ำ de abril de 1945.

45 AHPUIC, $I I I, S D G$, 66, Correspondencia Arturo Monzón, "Informe mensual y notas sobre la finca”, y AHPUIC, III, SI, 4, Monzón, Arturo, "Notas sobre la finca", p. 1. 


\section{Imagen 2}

\section{UTSIIONTAIRIO.}

\section{Union Fronterizo}

Datos solicitudos por la expedición científica del INSTITUTO INDIGE NISTA INTERAMERICANA, Estudios sociales sobre la ONCHOCERCO. SIS. agente hum ippal

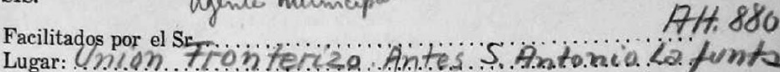
Cuantos habitantes centro,.............. \% otatine for

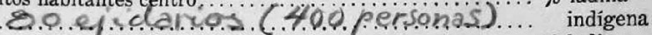

Habitantes en $\mathrm{l}$ Municipio ....................... \% ladina

Cuantas Escuelas

indígena

Estado .......Primaria ......... Secundaria .....

Productos:

mais, frijo piña, platono, camote, mango, tierra ricay fertie

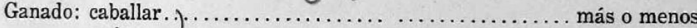

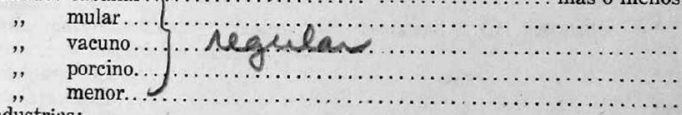

Industrias:

$$
\text { ningunes }
$$

Cuantos expendios de alcohol: I. de contrab ando mane = ........eantinas

....... fábricas jadopor un chino

Aumento del alcoholismo....... Și......

Qué campaña hay contra alcoholismo ...ñ

Servicio de salubridad.

Cuantos médicos particulares.

............

Hay dentistas?...

o.

Hospitales, cuantos.

Parteras......

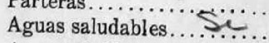

Agua potable......

\section{(tzimanes)}

Planta eléctrica .... 0 .......hidraulica

Carreterashevraduna voltaje y que clase forrasterna...

Teléfono ......

Telégrafo ......

Avión. 0

comunicando con motor

“Cuestionario Unión Fronterizo”, 1946, Biblioteca "Manuel Gamio”, PUIC-UNAM. Foto de la autora. 
de defensa que probablemente levantarán los dueños de las Fincas" por ese informe. ${ }^{46}$

\section{Imagen 3}

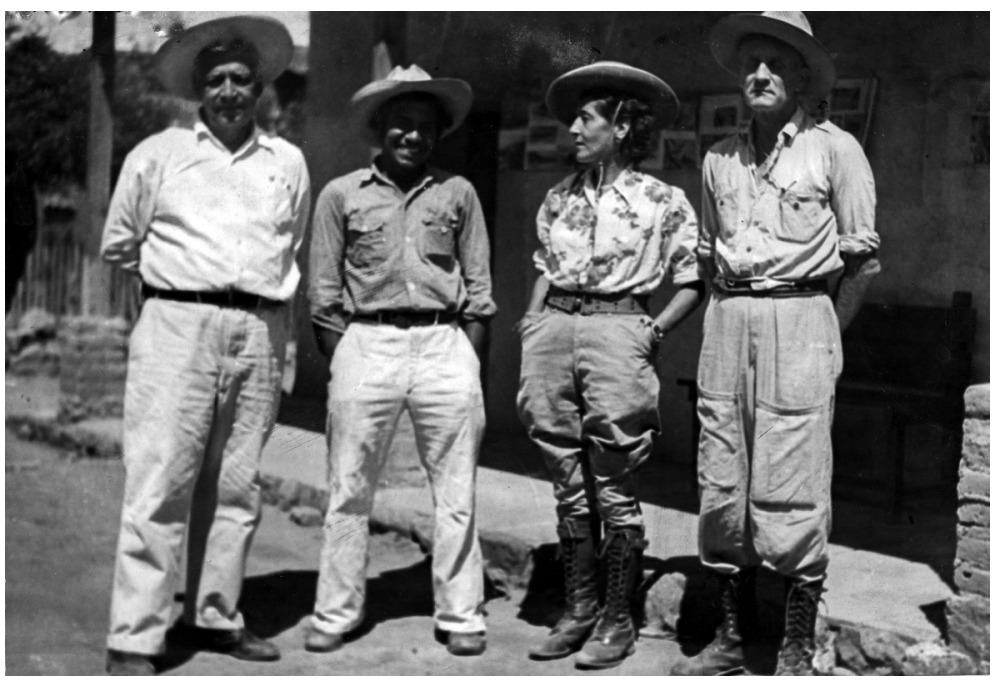

El grupo de Frans Blom. Archivo Histórico Asociación Cultural Na Bolom, San Cristóbal de Las Casas, Chiapas, México, c. 1, carp. 1007, p. 26.

Por su parte, F. Blom entregó un informe intitulado "Migraciones de la oncocercosis" que describe -acaso por vez primera en términos socio-antropológicos- todo el sistema de enganches y contratación de jornaleros en Los Altos hasta las fincas, por los Puestos de Vigilancia de salud y el retorno a sus pueblos de origen en Los Altos. ${ }^{47}$ Gracias a este informe es posible entender, por un lado, cómo funcionaban las relaciones

${ }^{46}$ AHPUIC, III, SDG, 66, Correspondencia Arturo Monzón, "Carta de Monzón a Gamio", 1을 mayo de 1945.

${ }^{47} \mathrm{Al}$ comparar este informe con los diarios de viaje queda claro que quien realizó esta parte de la investigación fue Gertrude Duby. Actualmente preparo 
laborales entre fincas y mano de obra, incluyendo la mediación del Sindicato de Trabajadores Indígenas, creado hacía menos de diez años. Según se explica, existían tres tipos de trabajadores: "contratados (enganchados); ganadores y ganador de contrabando". Los primeros pasaban por el enganchador, el Puesto de Vigilancia y el Sindicato de Trabajadores Indígenas; los segundos iban a la finca por su propia cuenta, ganaban mejor que el contratado y no pasaban por ninguna vigilancia sanitaria. En cuanto al tercero, se refería a aquellos ganadores sanos que iban a fincas infectadas de contrabando o viceversa: "un contratista llega con dijemos [sic] 25 trabajadores contratados para una finca infectada. Cinco de ellos son sanos [...] Pero el contratista debe entregar veinte y cinco $[s i c]$ trabajadores y no tiene otro contrato con una finca sana. Entonces y sin escrúpulos él envía los 5 sanos a la finca infectada". ${ }^{48}$ Todo el salario pasa por el contratista, quien envía una parte a los familiares y el resto se paga al regreso a Las Casas para evitar que se los roben o lo beban en el camino. Ya en la finca, los administradores "miran al trabajador como una especie de animal creado únicamente para traer cajas de café desde el cafetal hasta el beneficio. Viven bien protegidos tras telas de alambre mientras los trabajadores están expuestos al piquete de la ochraceum todo el día”. Además, muchos cosecheros, antes de volver a sus pueblos, se van a otras fincas de ganadores, donde los aceptan sin importar si están sanos o infectados. El regreso se hace sin conductor ni control alguno del estado de salud. Los trabajadores gastan todos sus viáticos en alcohol y suelen vender todo lo que llevan consigo y "no vuelven a la oficina de vigilancia hasta la próxima vez quiere $[s i c]$ ir a 'ganar' en las fincas". ${ }^{49}$

la publicación de las bitácoras, diarios, fotografías y acuarelas relativos a este viaje.

48 AHPUIC, III, SI, 4, Frans Blom, "Informe preliminar migraciones de los onchocercosos de Chiapas, México”, pp. 23, 49.

49 AHPUIC, III, SI, 4, Frans Blom, “Informe preliminar”, pp. 45, 82. 
Por otro lado, este texto da cuenta de los medios -altamente insuficientes- que los gobiernos federal y estatal habían establecido para controlar la enfermedad. Existían tres Puestos de Vigilancia en Chiapas: uno en Motozintla, encargado principalmente de atender a los jornaleros provenientes de El Bejucal y La Grandeza y que, "son tanto indios como ladinos"; el segundo, en Comitán, "vigila la zona de Comitán y Zapaluta (Trinitaria) y la mayoría son ladinos”. Y por último, el más grande, se ubicaba en San Cristóbal de Las Casas y quedaba a cargo de la población de Los Altos, "fuente inagotable de trabajadores para todos los grandes negocios de Chiapas". La cifra de trabajadores revisados en este último Puesto de Vigilancia, fue de 9222 para 1944, atendidos por apenas un solo enfermero y un secretario, quienes "estaban mal pagados y peor surtidos de instrumentos" y, sobre todo en tiempos de cosecha, se encontraban totalmente rebasados. ${ }^{50}$ Lo más tardado era cotejar minuciosamente el registro de las fincas en donde cada trabajador había estado, según los datos proporcionados por el contratista y los libros del Puesto de Vigilancia para asegurarse de no enviar trabajadores sanos a fincas contagiadas y viceversa. Luego, el enfermero revisaba al trabajador para conocer su estado de salud y buscar los quistes producidos por la oncocercosis. Finalmente, este mismo enfermero debía operar a quienes encontrara con quistes, tras lo cual determinaba si el trabajador iría a una finca sana o a una infectada. El resultado final podía tardar días o semanas, lo que provocaba que "por evadir dicho procedimiento [los trabajadores] se presentan por su propia cuenta" a las fincas. Algo similar sucedía con las brigadas sanitarias (nueve para toda la región del Soconusco): no había suficientes, debían abarcar extensiones muy grandes y tenían pocos empleados, con malos salarios y pocos instrumentos. Tampoco había ninguna vigilancia ni revisión a los trabajadores a su vuelta

${ }^{50}$ AHPUIC, III, SI, 4, Frans Blom, “Informe preliminar”, pp. 50, 51, 47. 
de las fincas, que es cuando probablemente ya habían quedado infectados. Y, sobre todo, los únicos que estaban vagamente "controlados" eran los trabajadores. Ni los pequeños comerciantes que circulaban en las mismas rutas que los trabajadores o que vendían en las fincas, ni los arrieros, cocineros y demás empleados estaban obligados a ser revisados. Son los llamados "no controlados" y que para Blom constituyen un factor capital de transmisión. Con base en esa información, el diagnóstico y las sugerencias de Blom solo podían ir en una dirección: "El ochráceum es el enemigo público número uno [...] Los contratistas y dueños de las fincas cafeteras son los enemigos públicos número dos. Se debe multar o encarcelar a ellos si no cumplen con las leyes. [...] El control está ineficaz [sic] por falta de doctores y enfermeros suficientes". ${ }^{51}$

Blom y su equipo extienden su investigación al estado de Oaxaca en vista de que existe información sobre la presencia de esta enfermedad en la Sierra Norte. ${ }^{52}$ No hay espacio aquí para detallar la narración de este largo recorrido desde el Istmo hasta los Valles Centrales, llena de detalles sobre los pueblos, sus habitantes y las experiencias de estos viajeros por las escarpadas y en ese entonces apenas recorridas sierras de la Zona Mixe y la región Sierra Norte. La enfermedad se hace presente solo en algunos de los pueblos visitados, en un vago perímetro que iría, aproximadamente de oriente a occidente, empezando por Camotlán, hacia Juquila Mixes y hasta Ixtlán, pasando por Villa Alta y todos los pequeños poblados y rancherías que los rodeaban.

Aquí, la situación contrasta fuertemente con Chiapas: "En Oaxaca no hay grandes fincas de café a donde van cantidades de

51 AHPUIC, III, SI, 4, Frans Blom, “Informe preliminar”, pp. 38, 32, 40, 137-138.

${ }^{52} \mathrm{Al}$ parecer, quien primero describe la enfermedad en Oaxaca es el doctor José E. Larumbe. E. Larumbe, "La onchocercosis en Oaxaca”, El Universal (25 abr. 1925). En AHNB, 2, 38,007. 


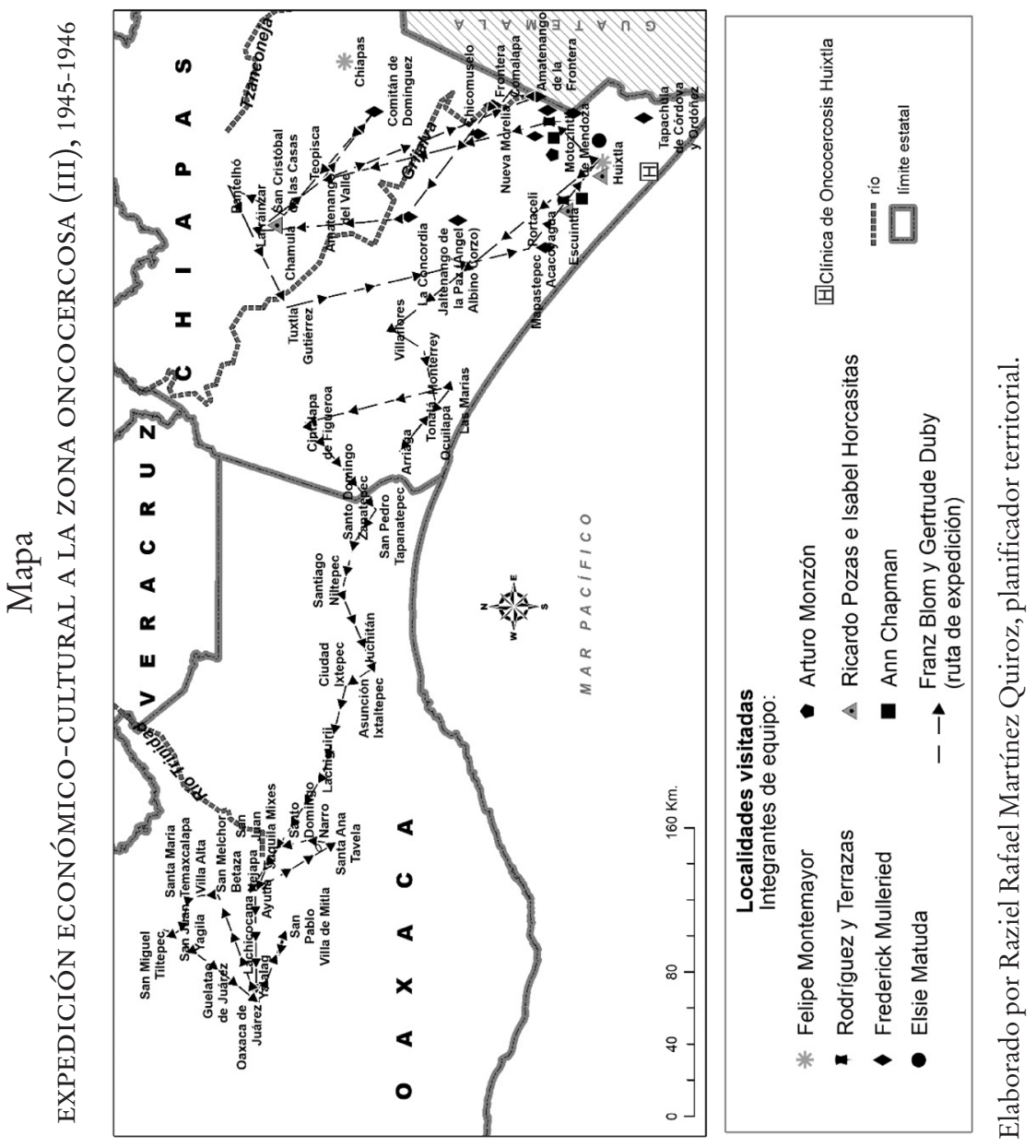


trabajadores y cosecheros. Los cafetales de Oaxaca son chicos, propiedad de una familia o una pequeña comunidad. Su producción es insignificante y la cosecha se hace por los mismos dueños del cafetal, ayudado por unos amigos". ${ }^{53}$ Ello no impide, sin embargo, que la situación pueda llegar a ser dramática también en esta región. Al grado que los viajeros rebautizan el pueblo de San Miguel Tiltepec como "Tiltepec de los ciegos”, descripción con la que cierro esta sección:

Café frente a las casas y café en el patio de atrás. Café cerro arriba y café cerro abajo. El pueblito está ahogado en un cafetal y en la sombra del café se esconde la ceguera [...] Son casas humildes y sus moradores son gente humilde. Y todos, sin excepción, están marcados por el onchocercosis. Sus facciones de la cara está [sic] esponjado, la nariz ancho y aplastado, el blanco de sus ojos es de color café. La gran parte de ellos caminan con la vista a la tierra y muchos están ciegos y andan con un bastón [...] La sombra del onchocerosis ha envuelto al pueblo. ${ }^{54}$

Contrariamente a lo sostenido por Gamio en su informe, lo que se desprende de las investigaciones de campo es que la oncocercosis no está presente en toda la región sino en subregiones precisas, estrechamente vinculadas a la producción de café. Asimismo, queda claro que, además del problema sanitario, existía un problema sociopolítico de falta de intervención estatal para controlar a las fincas y sus contratistas. Veremos, en la sección siguiente, qué pasa con el supuesto vínculo entre oncocercosis e indigeneidad que sirvió para justificar la colaboración del III en este proyecto.

53 AHNB, 2, 38,007, “Texto. Libro III”, s. p.

${ }^{54}$ AHNB, 1, 1,008, “Cuestionario y notas de Tiltepec", pp. 2-6. 
Observadores y observados: "... aqui puro ladino y japón es lo que abunda...”

A su llegada a Acacoyahua, pueblo del Soconusco fronterizo con Guatemala y catalogado como altamente infectado, Ricardo Pozas e Isabel Horcasitas se presentan en la Agencia Municipal y se instalan en la escuela pública. ${ }^{55}$ Muy pronto, sin embargo, Pozas constata que ese indígena que la antropología debía estudiar y el indigenismo intervenir no era fácil de encontrar en el cotidiano de los pueblos. Así lo manifiesta en correspondencia al director del III: "Con sorpresa vimos que a pesar de habérsenos dicho que era un pueblo de indígenas no hay uno solo pues aquí puro ladino y japón es lo que abunda". ${ }^{56}$ A nombre de Gamio, Juan Comas le responde que la decisión de investigar ese pueblo fue -una vez más- decidida por los médicos: "el Dr. Luis Figueroa [...] nos dijo que el porcentaje indígena era muy elevado en dicho pueblo". Sin embargo, agrega Comas, no ve inconveniente en que esto no sea así pues "siendo gente autóctona de la región, aunque sean ladinos en parte, suponemos que la investigación llegará a los fines propuestos". Y Comas agrega una posdata en la que aclara que "el criterio que guía al Instituto [...] es considerar indígenas a aquellos que tienen características culturales de tipo indígena, sin que tenga nada que ver su mayor o menor porcentaje de sangre indígena $[\ldots . .]^{3}{ }^{57}$

Así, saber quién era indígena estaba lejos de ser un dato objetivo y evidente, incluso en una región como Chiapas. Donde los médicos veían indígenas, el antropólogo veía ladinos. Pero sobre todo, saber con qué criterios podía atribuirse esa identificación

55 AHPUIC, III, SDG, 75, Ricardo Pozas, "Carta de Pozas a Comas", 11 de enero de 1945.

${ }^{56}$ AHPUIC, III, SDG, 75, Ricardo Pozas, "Carta de Pozas a Comas", 11 de enero de 1945.

57 AHPUIC, III, SDG, 75, Ricardo Pozas, “Carta de Comas a Pozas”, 18 de enero de 1945. 
seguía siendo un debate abierto: Comas señala que la "sangre" no es un criterio prioritario para el III (aun si Pozas nunca la menciona) y que más bien deben utilizarse como guía las "características culturales" ${ }^{58}$ Pero esas características eran precisamente las que Pozas no encontraba (por ejemplo al señalar que no se hablaban lenguas autóctonas), no obstante lo cual, el III insiste en continuar investigando ahí. Estos desfases de sentido permiten sugerir que esta exploración constituye un primer momento en que el “indio" que Gamio tenía en mente -más teórico que empírico- se confrontará con el caos y la inestabilidad de la experiencia de campo, obligando al III a hacer excepciones a su propio modelo y a modificarlo eventualmente.

La pertinencia de la asociación entre indigeneidad y oncocercosis es igualmente matizada en los documentos redactados por Blom en relación con los jornaleros chiapanecos en las fincas. Vale remarcar, en efecto, que en casi ningún pasaje de estos reportes se habla exclusivamente de indígenas (salvo en lo referente al Sindicato en San Cristóbal). Por ejemplo, al hablar del origen "étnico" y socioeconómico de los jornaleros, Blom explica que "todavía el trabajo en las fincas es trabajo de los pobres. Un indio, decimos [sic] de Chamula, que tiene su rancho, sus vacas y algunas mulas no se va a trabajar para 'ganar' en una finca cafetera, pero un ladino o indio pobre puede ganarse fácilmente un poco de dinero cosechando café". Además de una división de clases dentro de los pueblos, hay también distinciones entre pueblos. La mayoría de los jornaleros proviene de Chamula, mientras que los de Pantelhó y Chenalhó van, casi todos, a trabajar a las fincas del norte del estado, donde la problemática es distinta. Los habitantes de Zinacantán no participan de esta economía ni "los tzeltales de Ocosingo [quienes] casi

${ }^{58}$ Este argumento era el que, a fin de cuentas, para Gamio prevenía al indigenismo del racismo más rampante, aun si su clasificación no logró escapar del mismo evolucionismo que pretendía criticar. 
nunca se prestan al servicio en las fincas cafeteras". En los otros puestos de vigilancia encargados de la zona de El Bejucal, La Grandeza y Comitán, en contraste, "la mayoría son ladinos". ${ }^{9}$ Contrariamente a los presupuestos del III, ni todos los jornaleros de las fincas eran indígenas, ni todos los indígenas iban a las fincas. Cabe entonces preguntarse, al menos, si dicha distinción era operativa en el campo y en relación con la oncocercosis y su relación con las fincas.

La investigación en la finca La Esperanza lleva a Monzón al pueblo vecino de San José Ixtepec, con el cual existía un conflicto agrario sin resolver y en donde la alteridad cultural presupuesta por el III vuelve a difuminarse. Ahí Monzón anota que tras presentarse, el agente municipal “se puso muy contento y me dijo que tenían problemas importantes y que ya se habían realizado juntas para resolver entre ellos mismos algunos de los más importantes. Añadió que iba a aprovechar mi estancia para hacer una junta de jefes de familia [...] No hubo más remedio que hacerlo así, y traté de salir lo mejor posible" ${ }^{60} \mathrm{Al}$ final de la asamblea se redacta un acta dirigida al gobernador del estado (cuya copia Monzón envía a Gamio) en donde se señalan los principales problemas del pueblo: "el abastecimiento de agua potable, el del mejoramiento de la producción agrícola, el de la educación institucional y el de salubridad”. Al respecto del último punto, se propone que las brigadas operen a todos los enfermos cada vez que pasen y, sobre todo, que "[den] entrenamiento de enfermeros, para atender trastornos ligeros y los endémicos más comunes a uno o dos muchachos de la comunidad [..]”. ${ }^{61} \mathrm{Se}$ trata, tal vez, de una de las primeras formulaciones que anuncian a una de las figuras más emblemáticas del indigenismo

59 AHPUIC, III, SI, c. 4, Blom, “Informe preliminar”, pp. 22, 23, 50.

60 AHPUIC, III, SDG, 66, Correspondencia Arturo Monzón, "Carta de Monzón a Gamio”, 1o de mayo de 1945.

${ }^{61}$ AHPUIC, III, SI, 4, Arturo Monzón, "Informe mensual y notas sobre la finca", “Acta de la asamblea”, 21 de abril de 1945, pp. 1-3. 
promovido por el INI a partir de la década siguiente: los "promotores culturales indígenas". ${ }^{62}$

Esta misma propuesta aparece en un Proyecto de atención médica que redacta Anne Chapman, la otra etnóloga contratada por el III, tras su visita a las colonias agrarias del municipio de Ángel Albino Corzo. Chapman envía ese escrito a Gamio, al secretario de Salud y al gobernador de Chiapas, y su contenido sólo puede deducirse a partir de la respuesta que redacta el doctor Figueroa, jefe de la campaña oncocercosa en Chiapas. En dicha respuesta, Figueroa asegura que la región en cuestión "está siendo atendida con toda regularidad desde el punto de vista de la oncocercosis", pero que tal vez las demandas expresadas en el proyecto de Chapman se vinculen con necesidades "asistenciales más bien que sanitarias", lo cual atañe a otras jurisdicciones (estatal, municipal, ejidal). Reconoce, además, que es imposible que la región en cuestión reciba asistencia médica (esto es, más allá de la atención a la oncocercosis) "tanto por su lejanía $[. .$.$] como porque las dos Brigadas que atienden esa$ región carecen frecuentemente de médico". Y para terminar, un comentario revelador del desafío que, poco después, supuso la implementación del programa de formación de "promotores indígenas". Dice Figueroa: "Por último, deseo no dejar inadvertidos el peligro e inconvenientes que desde diversos puntos de vista entrañaría designar entre los mismo [sic] habitantes de la región, dado que la mayoría de los adultos son analfabetos, a los 'enfermeros' que se proponen en el proyecto". ${ }^{63}$

Años más tarde, los recuerdos plasmados por esta antropóloga respecto de su participación en el Proyecto Oncocercosis

${ }^{62}$ Otra referencia (pero más tardía), que al menos Manuel Gamio suele citar en sus escritos, es un trabajo del antropólogo Michel Pijoan sobre un proyecto de medicina entre los miskitos de Nicaragua, publicado en América Indígena en 1946. Pijoan, "The Health and Customs".

63 AHSSA, SSA, SubSyA, 3, 10, 1944-1945, fs. 113-5, "Respuesta del director de campaña contra la oncocercosis", 8 de mayo de 1945. 
son más explícitos respecto de la postura política de esos jóvenes antropólogos en el campo:

Como no estaba segura de que nuestros estudios iban a beneficiar a las comunidades, en casi cada ejido que visité reunía a los hombres y a las mujeres para [...] preguntarles cuáles eran sus necesidades más apremiantes. Casi siempre se trataba de poder contar con una clínica, más o mejor atención médica para atender la oncocercosis [...], instalar una escuela primaria, u obtener ayuda para incrementar su producción de café, maíz o frijol [...] Luego de elaborar la petición [...] la enviaba al gobernador de Chiapas, y los ministros correspondientes [...] en la Capital. Esta iniciativa mía no fue del agrado del director, mi patrón. Pero cuando se dio cuenta de lo que hacía, ya casi había terminado el estudio. ${ }^{64}$

Si bien esos informes no se hallan ni en el III ni en el Archivo de Salud, una correspondencia entre Gamio y Figueroa de finales de abril de 1945 trata del asunto: el doctor Figueroa aclara que ha expresado verbalmente a Chapman que esa acción era inadecuada y le indica igualmente a Gamio que tiene la sospecha de que Pozas está haciendo lo mismo. La solución que Gamio propone, sin medias tintas, es que se les indique a ambos investigadores que, "de mantener estas acciones, todo pago de sus emolumentos se detendrá”. ${ }^{65}$

Las sospechas de Figueroa respecto de Pozas eran correctas, como se verá enseguida. Desde Acacohuaya, Pozas se traslada a Chamula, con el fin de estudiar a los jornaleros que trabajan en las fincas. Durante su estancia en Los Altos, se encuentra

64 Chapman, Genealogía de mis profesores, p. 12, citado en GonzÁlez MonTES, “Anne MacKaye Chapman”, p. 23. A partir de esta narración, se puede suponer que la asamblea consignada por Monzón hubiera sido convocada por él mismo.

65 AHSSA, SSA, SubSyA, 3, 10, 1944-1945, F176, "Carta de Luis Figueroa a Manuel Gamio”, 21 de abril de 1945. 
con el gobernador del estado, de gira en ese mismo pueblo, acompañado por el director del Museo de Arqueología de Tuxtla, Bernardo Reyes, quien había sido clave en la realización de proyectos etnográficos previos. ${ }^{66}$ Pozas comenta con él "los problemas que estamos estudiando en el estado [ante lo cual Reyes] me invitó para que formulara un plan de trabajo para Chamula [destinado] al señor gobernador" ${ }^{67}$ Sin embargo, lejos de recibir una respuesta positiva frente a la posibilidad de mostrar ante el gobierno la utilidad del trabajo antropológico, Gamio le pide que se retracte: "Abrigo los mejores propósitos de que colaboremos con el Gobierno del Estado [...] pero si anteriormente se da al señor Gobernador toda clase de datos sobre los trabajos que estamos efectuando, ya no podríamos aspirar a lo arriba mencionado" ${ }^{68}$ El resultado es que Pozas se ve obligado a solicitar a Reyes que no entregue su proyecto al gobernador, explicando que "no soy sino un empleado técnico del III y es el Dr. Gamio el indicado para tratar con el Gobernador del Estado todos los asuntos del trabajo práctico y entre ellos los que se desprendan del proyecto para el pueblo de Chamula". ${ }^{69}$ La utilidad de la antropología tan buscada por Gamio se hacía evidente para los investigadores de campo, aun si por veredas imprevistas que no parecen haber sido de su agrado. Ya fuera porque, como reconoce Pozas en otra misiva, "se salvaban los conductos debidos" para tratar con el gobierno, ${ }^{70}$ lo cual en otras palabras equivalía a decir que se desdibujaba la posición del

${ }_{66}$ Específicamente de la expedición a Zinacantán dirigida por Sol Tax en 1942 y en la cual Pozas participa.

${ }^{67}$ AHPUIC, III, SDG, 75, Ricardo Pozas, "Carta de Pozas a Gamio", 13 de abril de 1945 .

68 AHPUIC, III, SDG, 75, Ricardo Pozas, "Carta de Gamio a Pozas", 24 de abril de 1945.

69 AHPUIC, III, SDG, 75, Ricardo Pozas, “Carta de Pozas a Reyes”, 26 de abril de 1945.

70 AHPUIC, III, SDG, 75, Ricardo Pozas, "Carta de Pozas a Gamio", 24 de abril de 1945. 
director del proyecto. $\mathrm{O}$, más probablemente, porque los resultados y las demandas recogidos por los antropólogos suponían una denuncia abierta al orden imperante, del cual las instituciones gubernamentales eran parte constitutiva.

Para terminar, una larga y vívida descripción de Blom muestra, una vez más, lo complicada que resultaba la premisa cultural en el caso estudiado. Se trata de la visita que hicieron a la colonia Unión Fronteriza, cercana a la frontera con Guatemala:

Nunca, escribe Blom, ${ }^{71}$ en todos mis viajes he visto tanta abundancia [...] Una riqueza de colores, [orquídeas] colgaban de los robles como tantas hierbas cualquieras [...] Así llegamos a la Colonia Unión Fronterizo [sic] (antes San Antonio La Junta), a unas dos leguas (6-8 km de la frontera con Guatemala) [...] Es tierra fértil y rica [...] Pero como [está] lejos de los mercados, no pueden vender sus productos con facilidad, por lo que tienen que salir a las fincas cafeteras $[\ldots]$ y con esto viene la horrible miseria del pueblo. Cien por ciento de la gente son onchocercosos.

Al llegar, visitaron al agente municipal, quien apenas si podía leer sus credencias debido a la ceguera causada por la enfermedad.

Apenas habíamos desempacado nuestro equipo cuando empezaron a llegar los enfermos de todos lados, preguntando cuándo íbamos a operar las bolas. Todos creían que éramos miembros de una Brigada onchocerca [...] Familias enteras, hombres y mujeres con un niño a la mano, otro abrazado y un tercero en el rebozo. Llegaron ancianos ciegos buscando su camino con un bastón y jóvenes fuertes pero enfermos. Todos, todos tenían las señas del onchocercosis, piel dura de la cara, ojos brillantes y sucios o rojos en el blanco. Todos miraban para el suelo evitando la luz fuerte del sol. Muchos habían

${ }^{71}$ Es posible que este reporte lo haya redactado Gertrude Duby, aunque no está firmado. 
sido operados seguidas veces, otros nos mostraban sus bolas en la cabeza o en el cuerpo [...] Después de ser revisada la gente, se sienta frente a la escuela para platicar, cambiar cuentos y reírse del sol. Una marimba toca alegremente en una casa vecina [...]. No hablan de su enfermedad, pero se quejan porque no hay maestros para la escuela. Quieren educar a sus hijos e hijas. El último maestro se huyó por miedo de la enfermedad. Preguntan si sabemos cuándo llega la Brigada para curarlos, quieren vivir, quieren ver. ${ }^{72}$

Sin duda, el tono lírico de esta dramática narración debe tomarse con reservas; aun así, este extracto muestra cómo la problemática social vinculada a la oncocercosis estaba lejos de estar atravesada por un factor "étnico", como lo suponía Gamio. Menos aún se encontraban los sujetos identificados como "indígenas" inmersos en creencias primitivas o temerosos de la medicina. Al contrario, este y muchos otros testimonios dejan ver cómo los grupos identificados como indígenas estaban plenamente incorporados al mercado laboral y conocían y exigían que la medicina "moderna" los atendiera. A nivel de campo, el problema no era uno de traducción cultural sino de ausencia del Estado, ya fuera para aumentar la inversión pública en salud o para obligar a los dueños de las fincas a acatar la ley. Todo lo cual no dejaba lugar a dudas en cuanto a la utilidad de la antropología. Ésta no consistía en mediar entre culturas distintas sino en transmitir los problemas de los habitantes rurales a las instancias competentes o, como en el caso de Monzón, formular soluciones potenciales. En suma, además de las diferencias en el modo de concebir a los sujetos estudiados y su relación con la enfermedad, se abría una fractura más entre el conceptor y director del proyecto y los investigadores en el campo, esta vez sobre su propio papel y la función de la antropología a escala local.

72 AHPUIC, III, SI, c. 4, “Anexo: Unión Fronteriza”, pp. 1-4. 
INSTRUMENTALIZAR LA ALTERIDAD PARA CONSTRUIR INSTITUCIONES Y EXPERTOS

Ciertamente, el llamado Proyecto Oncocercosis fue un proyecto pequeño, con un impacto social y político matizado y que no tuvo consecuencias directas ni a nivel local ni a nivel federal. No obstante, he querido mostrar aquí que, al desplazar el análisis más allá de los resultados concretos del proyecto, se puede atender a las contradicciones, limitantes, retos y tensiones que condicionaron su ejecución práctica, muchas de las cuales seguirán determinando los proyectos indigenistas posteriores. Para ello, la metodología adoptada en este artículo consistió en poner al descubierto las dos facetas de la "Exploración económico-cultural": su génesis -incierta y atribulada- y su puesta en práctica-experimental y heterogénea-, beneficiándome de materiales que apenas empiezan a ser analizados históricamente, como las correspondencias y los diarios de campo de antropólogos e indigenistas.

$\mathrm{Al}$ adentrarse en aquellos senderos se constata que, para mediados de la década de 1940, cuando este proyecto se concreta y se pone en práctica, el indigenismo como doctrina de intervención pública no tenía aun un perfil estable, definido, tanto frente a otros expertos, como hacia el interior mismo del área de expertise que se estaba tratando de esbozar. Al contrario, aquí he podido documentar las dificultades que Manuel Gamio encontró a lo largo de la planeación del proyecto, no solo para llevarlo a cabo sino para mostrar, sobre todo frente a los médicos, que el III podía ofrecer un método de intervención pública singular y pertinente para resolver un problema social específico -cómo integrar a la nación moderna a una población marginada, los indígenas-. Esta indefinición práctica del proyecto indigenista se tradujo, concretamente, en que ni al momento de la distribución de fondos, ni en la decisión de qué lugares investigar, ni en los resultados propuestos, el in y su proyecto de acción pública ocuparon una posición de fuerza o de poder que le permitiera 
incidir en la transformación social que buscaba. Esta evidencia invita entonces a repensar las cronologías más usuales que esbozan una historia continua del indigenismo desde la publicación de Forjando Patria en 1916 hasta la creación del Instituto Nacional Indigenista en 1948.

Con el fin de hacer visible la especificidad de cierta perspectiva indigenista y de posicionar al III, la estrategia de Gamio consistió en esbozar a un sujeto social -el indígena-cuyo rasgo principal era ser radicalmente otro en términos culturales (y evolutivos, cuando habla de primitivismo). Este argumento de la alteridad radical era indispensable para justificar la mediación del antropólogo y, en última instancia, la existencia de una política específica dirigida a grupos particulares. Esta justificación parece haber tenido cierto éxito si se considera que es gracias a dicho argumento que el III logra finalmente participar -aun si marginalmente- en el proyecto médico sanitario que la OSP termina controlando. Asimismo, a pesar de que se trató de un proyecto pequeño que casi ni figura en la historia del indigenismo, el otro triunfo de Gamio consistió en fijar, en su informe final, una "verdad" sobre los pobladores de la zona estudiada, a saber, que su principal característica y su mayor problema era la especificidad cultural. Verdad que se perpetuó por medio de los proyectos gubernamentales siguientes, en particular el INI.

Esa verdad, sin embargo, no fue necesariamente compartida por quienes, en el modelo de Gamio, serían los aliados naturales del indigenismo: los antropólogos involucrados en el proyecto. Al desplazar la mirada hacia la ejecución concreta del proyecto, al nivel del terreno y de las interacciones más encarnadas que los antropólogos reportan, he mostrado que ese indígena culturalmente distinto del ideal-tipo nacional, que anteponía sus creencias a los beneficios de la ciencia, aislado y marginado de la economía nacional, fue casi imposible de encontrar en todos los recorridos y estancias de los antropólogos en la zona oncocercosa de Chiapas y Oaxaca. O, por lo menos, no es el sujeto 
que se dibuja en las demandas y problemas recopilados por los antropólogos. En estas quejas no hay testimonios que refieran a la protección, defensa o reconocimiento de una especificidad cultural, sino al contrario. Lo que se pide es mayor presencia del Estado, mayores derechos ciudadanos, que la ley se cumpla, que la salud pública y la educación lleguen a todos los rincones de la zona. En suma, donde los investigadores de campo veían una presencia deficiente del Estado, Gamio veía alteridad cultural. Donde los entrevistados, vía los investigadores de campo, solicitaban más salud y educación, Gamio respondía que era necesario entender y transformar la diferencia cultural, sin lo cual las necesidades económicas no podrían ser resueltas. Se trataba, al fin y al cabo, de satisfacer las necesidades más básicas de grupos incomprendidos por su cultura, argumento que resultaba más fácil de articular al discurso gubernamental que la transformación de las relaciones de poder a nivel regional. Es así que, si acaso el "culturalismo" de Gamio dominó de alguna manera las publicaciones de la década de 1940, como suele narrar la historia de la antropología, queda claro, al analizar el trabajo cotidiano en el campo, que no era la única -ni tal vez la principal- tendencia antropológica ni indigenista en ese momento. ${ }^{73}$ Más bien, su postura estaba siendo fuertemente cuestionada, tanto por la tendencia más sociológica y política de los antropólogos de la siguiente generación, como por los datos que el trabajo de campo permitía obtener.

A la luz de este caso, entonces, la crítica generalizada desde la década de 1970 que se le hace al indigenismo, de que negó y buscó eliminar las culturas indígenas (el llamado "etnocidio") a favor de cierta homogeneidad nacional, puede problematizarse. ${ }^{74}$

73 Véase entre otros Hewitt, Imágenes del campo; Portal y Ramírez, El pensamiento antropológico, y más recientemente González MuÑIz, "Un trato directo con gentes y cosas".

74 Véase Warman et al., De eso que llaman...; Barabas y Bartolomé, "Hydraulic development and Ethnocide". 
Más allá de evaluar las acciones gubernamentales, el problema es que esta crítica asume sin cuestionamientos que la alteridad radical de ciertos grupos es un dato objetivo e incontrovertible. La evidencia aquí mostrada, en cambio, abre la pregunta de si dicha alteridad radical estaba presente en el campo observado por los antropólogos. Es más, el indigenismo que estaba aquí esbozándose, lejos de ser un factor clave en la desaparición de cierta especificidad cultural atribuida a los grupos indígenas, fue clave en instrumentalizarla como la frontera que definiría a dichos grupos y sus necesidades, aun si estaba siempre en tensión con otras posturas que trataban de fijar otros marcadores sociales de diferenciación. En otras palabras, la "cultura" como marcador social sobresaliente para distinguir grupos dentro del cuerpo nacional en la década de 1940 resulta funcional y es exaltada pero para posicionar instituciones gubernamentales, expertos y métodos de intervención, e incluso, para condicionar una serie de acciones públicas que los habitantes rurales -mediante la participación de los antropólogos-, más allá de su pertenencia etnolingüística, parecían colocar al centro de sus preocupaciones (salud, educación, legalidad).

En suma, detallar este primer laboratorio de lo que después se llamará “antropología aplicada” permite revelar las tensiones que atravesarán el proyecto indigenista: por ejemplo, el imposible equilibrio entre constituirse en un proyecto de transformación social o en un proyecto gubernamental de domesticación del mundo rural que instrumentaba la cultura como condición sine qua non de dicho cambio social, incluso a costa de demandas sociales y ciudadanas. O también, las tensiones en la concepción misma tanto del sujeto del indigenismo -el indígena- como del antropólogo, como agente del cambio cultural o vocero de las necesidades de los habitantes rurales. Estas contradicciones no desaparecerán con la creación del Instituto Nacional Indigenista (INI), inaugurado en 1948. Al contrario, reconstruir las contradicciones ligadas al Proyecto Oncocercosis 
interesa también en la medida en que anuncian el indigenismo promovido por esa agencia gubernamental durante las décadas siguientes, permitiendo una comprensión de dicho plan como un proceso paulatino, contradictorio y multiforme.

Probablemente, estas continuidades entre una y otra institución, no resulten novedosas, aun si el periodo previo a la creación del INI sigue siendo, en gran medida, un territorio por explorar. Más sorprendente resulta la continuidad que se percibe en el discurso político y legal contemporáneos en los cuales la identificación como "indígena” sigue fuertemente determinada por aquella alteridad cultural, entendida, además, como una marca de resistencia y de legitimidad política que debe ser celebrada y mantenida. Queda aún por entender cómo se produjo esa inversión de posiciones. Aquí he querido apuntar únicamente un momento, tal vez fundador, en el que la cultura como naturaleza de un grupo y causa de una situación se instrumentalizó contra las demandas de transformación política, heredando, hasta hoy, la asociación entre sujeto social indígena $\mathrm{y}$ alteridad cultural como una premisa indiscutible.

\section{SIGLAS Y REFERENCIAS}

AHNB Archivo Histórico Asociación Cultural Na Bolom, San Cristóbal de Las Casas, Chiapas, México.

AHPUIC, III Archivo Histórico del Programa Universitario de la Diversidad Cultural e Interculturalidad, fondo Instituto Indigenista Interamericano, Universidad Nacional Autónoma de México, Ciudad de México, México.

SAE Sección Acervos Especiales

SDG Sección Dirección General

SI Sección Investigaciones

AHSSA, SSA, SubyA Archivo Histórico de la Secretaría de Salud, fondo Secretaría de Salubridad y Asistencia, sección Subsecretaria de Salubridad y Asistencia

Agostoni, Claudia, "Médicos rurales y medicina social en el México posrevolucionario (1920-1940)", en Historia Mexicana, LxIII: 2 (250) (oct.-dic. 2013), pp. 745-801. 
Barabas, Alicia y Miguel Bartolomé, "Hydraulic Development and Ethnocide: The Mazatec and Chinantec People of Mexico", en Critique of Anthropology, 1: 1 (1974), pp. 74-102.

Birn, Anne-Emmanuelle, "Wa(i)ves of Influence: Rockefeller Public Health in Mexico, 1920-1950", en Studies in History and Philosophy of Science, 31: 3 (2000), pp. 381-395.

Chapman, Anne, Genealogía de mis profesores e informantes, Buenos Aires, Universidad de Buenos Aires, Museo Etnográfico Juan B. Ambrosetti, 2004.

DAMPF, Alfonso, "La carretera panamericana y el problema de la oncocercosis", en Boletín de la Oficina Sanitaria Panamericana, 21: 8 (ago. 1942), pp. 753-758.

Dillingham, Alan Shane, "Indigenismo Occupied: Indigenous Youth and Mexico's Democratic Opening (1968-1975)", en The Americas: A Quarterly Review of Latin American History, $72: 4$ (2015), pp. 549-582.

Gamio, Manuel, "Consideraciones sobre el problema indígena en América", en América Indígena, II: 2 (abr. 1942), pp. 17-23.

Gamio, Manuel, "Calificación de características culturales de los grupos indígenas”, en América Indígena, II: 4 (oct. 1942), pp. 17-22.

Gamio, Manuel, "Exploración económico-cultural en la región oncocercosa de Chiapas, México”, en América Indígena, vi: 3 (jul. 1946), pp. 199-246.

Gamio, Manuel, "Las características culturales y los censos indígenas", América Indígena, II: 3 (jul. 1942), pp. 15-19.

Gamio, Manuel, Forjando Patria (Pro Nacionalismo), México, Porrúa, 1916.

García Mora, Carlos, Panorama histórico de la antropología en México, México, Instituto Nacional de Antropología e Historia, 1988, t. II.

Giraudo, Laura y Juan Manuel SÁNchez, La ambivalente historia del indigenismo. Campo interamericano y trayectorias nacionales 1940-1970, Lima, Instituto de Estudios Peruanos, 2011.

Gleizer, Daniela y Paula López Caballero, Nación y alteridad. Mestizos, indígenas y extranjeros en el proceso de formación nacional, México, Ediciones Educación y Cultura, 2015. 
GonzÁLEz Montes, Soledad, “Anne MacKaye Chapman. Testimonios y exploraciones”, en Medina y OchoA (eds.), 2007, pp. 21-35.

GonZález MuÑIz, Eduardo, "Un trato directo con gentes y cosas. Apuntes para una historia del trabajo de campo antropológico en México", en RuTsCH, y VerA, 2019, pp. 19-64.

Gudiño, María Rosa, Educación higiénica y cine de salud en México, 19251960, México, El Colegio de México, 2016.

Hansen, Thomas Blom y Finn Stepputat (eds.), States of Imagination. Ethnographic Explorations of the Postcolonial State, Durham, NC, Duke University Press, 2001.

Hernández, Rosalva Aída, Histories and Stories from Chiapas. Border Identities in Southern Mexico, Austin, University of Texas Press, 2001.

Hewitt de Alcántara, Cynthia, Imágenes del campo: la interpretación antropológica del México rural, México, El Colegio de México, 1988.

Legarreta, Patricia, "Ingeniería social en Mesoamérica. Revolución, intervención, desarrollo y cooperación internacional", tesis de doctorado en ciencias antropológicas, Mexico, Universidad Autónoma MetropolitanaIztapalapa, 2016.

LewIs, Stephen, Rethinking Mexican Indigenismo: The INI's Coordinating Center in Highland Chiapas and the Fate of a Utopian Project, Albuquerque, University of New Mexico Press, 2018.

López Caballero, Paula, “Las políticas indigenistas y la 'fábrica' de su sujeto de intervención en la creación del primer Centro Coordinador del Instituto Nacional Indigenista (1948-1952)”, en Gleizer y López Caballero, 2015, pp. 69-108.

López Caballero, Paula, "Anthropological Debates around the Indigenous Subject and Alterity, 1940-1948”, en López Caballero y Acevedo Rodrigo (eds.), 2018, pp. 199-221.

López Caballero, Paula y Ariadna Acevedo Rodrigo (eds.), Beyond Alterity. Destabilizing the Indigenous Other in Mexico, Tucson, The University of Arizona Press, 2018.

Medina, Andrés, "Ricardo Pozas en la trama de la antropología mexicana", en La Palabra y el Hombre, 91 (jul.-sep. 1994), pp. 21-67. 
Medina, Andrés y Ángela OchoA (eds.), Etnografía de los confines. Andanzas de Anne Chapman, México, Centro de Estudios Mexicanos y Centroamericanos, Instituto Nacional de Antropología e Historia, Universidad Nacional Autónoma de México, 2007.

Meza-Huacuja, Ivonne, "De la Universidad al campo. El establecimiento del servicio médico social en la Universidad Autónoma de México: (1934-1940)", en Historia Mexicana, LXIv: 2 (254) (oct.-dic. 2014), pp. 607-644.

Meza-Huacuja, Ivonne (coord.), Historia de las juventudes en América Latina, México, Universidad Nacional Autónoma de México [en prensa].

Montemayor, Felipe, Los efectos de la onchocercosis en la población de Acacoyahua, Chiapas, tesis de licenciatura en Antropología, Escuela Nacional de Antropología e Historia, 1954.

Morales, Claudia y Carolina Rivera, "De peones a ejidatarios: la lucha por la tierra en la zona cafetalera del Soconusco, Escuintla, Chiapas", en Cadernos de Estudos Sociais e Politicos, 5: 9 (ene.-jun. 2016), pp. 42-53.

Muñoz, María, Stand Up and Fight: Participatory Indigenismo, Populism, and Mobilization in Mexico, 1970-1984, Tucson, The University of Arizona, 2016.

Nielsen, Jesper, Restless Blood. Frans Blom, Explorer and Maya Archaeologist, Tulane, New Orleans, Middle American Research Institute, Tulane University, 2017.

Pijoan, Michael, "The Health and Customs of the Miskito Indians of Northern Nicaragua: Interrelationships in a Medical Program”, en América Indígena, vi: 2 (abr.-jun. 1946), pp. 157-184.

Portal Ariosa, María Ana y Xóchitl Ramírez, Elpensamiento antropológico en México, México, Universidad Autónoma de México-Iztapalapa, 1995.

Pozas Arciniega, Ricardo, "El trabajo en las plantaciones de café y el cambio sociocultural del indio", en Revista Mexicana de Estudios Antropológicos, XIII (1952), pp. 31-48.

Pozas Arciniega, Ricardo, "Los mames de la región oncocercosa del estado de Chiapas", en Anales del INAH, 32, t. IV, 1949-1950, sexta época (19391966) 1952, pp. 252-261.

Programa Nacional para la Eliminación de la Oncocercosis, La Oncocercosis en México [en línea], México, 2014, consultado el 5 de agosto de 2019 
disponible en https://www.gob.mx/cms/uploads/attachment/file/390792/ DOSSIER_MEXICO_18_NOVIEMBRE_2014_1.pdf

Robinet, Romain, “'Hermanos de raza’: La Confederación Nacional de Jóvenes Indígenas, entre el indigenismo y la política (años 1940 y 1950)”, en Meza-Huacuja (coord.) [en prensa].

Rutsch, M. y J. L. Vera, La antropología en México: a veinticinco años de su publicación, México, Centro de Estudios Filosóficos, Políticos y Sociales Vicente Lombardo Toledano, 2019.

SARIEgo, Juan Luis, El indigenismo en la Tarabumara: identidad, comunidad, relaciones interétnicas y desarrollo en la Sierra de Chibuabua, México, Instituto Nacional Indigenista, Instituto Nacional de Antropología e Historia, 2002.

Schwartz-Francisco, Diana, "Displacement, Development, and the Creation of a Modern Indígena in the Papaloapan, 1940s-1970s", en López CABALLero y ACEVEDo Rodrigo (eds.), 2018, pp. 222-243.

Schwartz-Francisco, Diana, "Transforming the Tropics: Development, Displacement, and Anthropology in the Papaloapan, Mexico, 1940s-1970s", tesis de doctorado en historia, Chicago,University of Chicago, 2016.

Téllez Ortega, Javier, “La época de oro (1940-1964)”, en García Mora, 1988, t. II, pp. 289-338.

VÁzquez, José Luis, "Cafeticultura e historia social de la oncocercosis en el Soconusco, estado de Chiapas”, en Salud Pública de México, 33: 2 (mar.-abr. 1991), pp. 124-135.

Warman, Arturo, Margarita Nolasco, Guillermo Bonfil, Mercedes Olivera y Enrique Valencia, De eso que llaman antropología mexicana, México, Nuestro Tiempo, 1970. 


\section{Anexo I}

GASTOS DEL III EN EL PROYECTO ONCOCERCOSIS

\begin{tabular}{lcccc}
\hline Investigador & $\begin{array}{c}\text { Ingreso } \\
\text { mensual }\end{array}$ & $\begin{array}{c}\text { Total } \\
\text { pagado }\end{array}$ & $\begin{array}{c}\text { Total } \\
\text { erogado }\end{array}$ & $\begin{array}{c}\text { Presupuesto } \\
\text { total }\end{array}$ \\
\hline & & 25275.00 & 29100.00
\end{tabular}

Felipe Montemayor García

Duración de la comisión $\quad 2.5$ meses

Gratificación mensual $\quad 150.00$

Viáticos a razón de 10.00/día $\quad 300.00$

Total / mes $\quad 450.00$

1125.00

Franz Blom

Duración de la comisión 6 meses

Gratificación mensual $\quad 450.00$

Viáticos a razón de 10.00/día $\quad 300.00$

Total / mes $\quad 750.00$

4500.00

Federico Mullerried

Duración de la comisión 3 meses

Gratificación mensual $\quad 250.00$

Viáticos a razón de 10.00/día $\quad 300.00$

Total / mes $\quad 550.00$

1650.00

Arturo Monzón

Duración de la comisión 6 meses

Gratificación mensual $\quad 150.00$

Viáticos a razón de 10.00/día $\quad 300.00$

Total / mes $\quad 450.00$

2700.00

Isabel Horcasitas

Duración de la comisión 6 meses

Gratificación mensual $\quad 150.00$

Viáticos a razón de 10.00/día $\quad 300.00$

Total / mes $\quad 450.00$ 
Anexo I

GASTOS DEL III EN EL PROYECTO ONCOCERCOSIS (concluye)

\begin{tabular}{ccccc}
\hline & Ingreso & Total & Total & Presupuesto \\
Investigador & mensual & pagado & erogado & total \\
\hline
\end{tabular}

Ricardo Pozas

Duración de la comisión 6 meses

Gratificación mensual $\quad 150.00$

Viáticos a razón de 10.00/día $\quad 300.00$

Total / mes

450.00

2700.00

Anne Chapman

Duración de la comisión $\quad 6$ meses

Gratificación mensual $\quad 250.00$

Viáticos a razón de 10.00/día $\quad 300.00$

Total / mes $\quad 550.00$

3300.00

Héctor Rodríguez

Duración de la comisión 6 meses

Gratificación mensual $\quad 250.00$

Viáticos a razón de 10.00/día $\quad 300.00$

Total / mes $\quad 550.00$

3300.00

Carlos Terrazas

Duración de la comisión $\quad 6$ meses

Gratificación mensual $\quad 250.00$

Viáticos a razón de 10.00/día $\quad 300.00$

Total / mes $\quad 550.00$

3300.00

Elaborado por la autora a partir de: AHPUIC, III, SAE Centro de información acervos especiales, CD Datos, Correspondencia 1940, "Informe sobre las funciones y actividades del Instituto Indigenista Interamericano durante el sexenio comprendido desde 1942 en que fue legalmente organizado hasta 1948", y de AHSSA, SS, SubSyA, 5, 17, 1945-1949, fs. 184-194. 


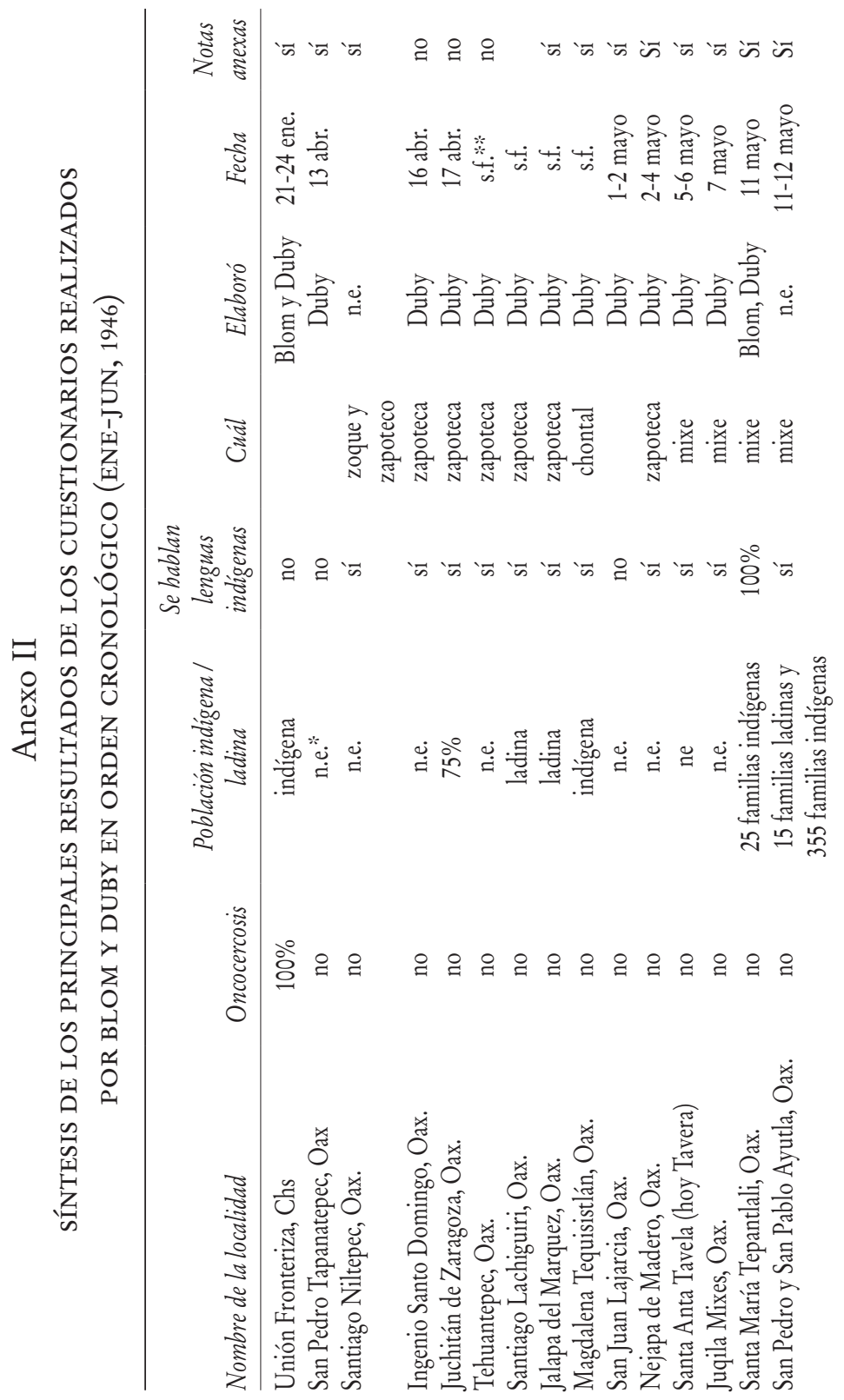




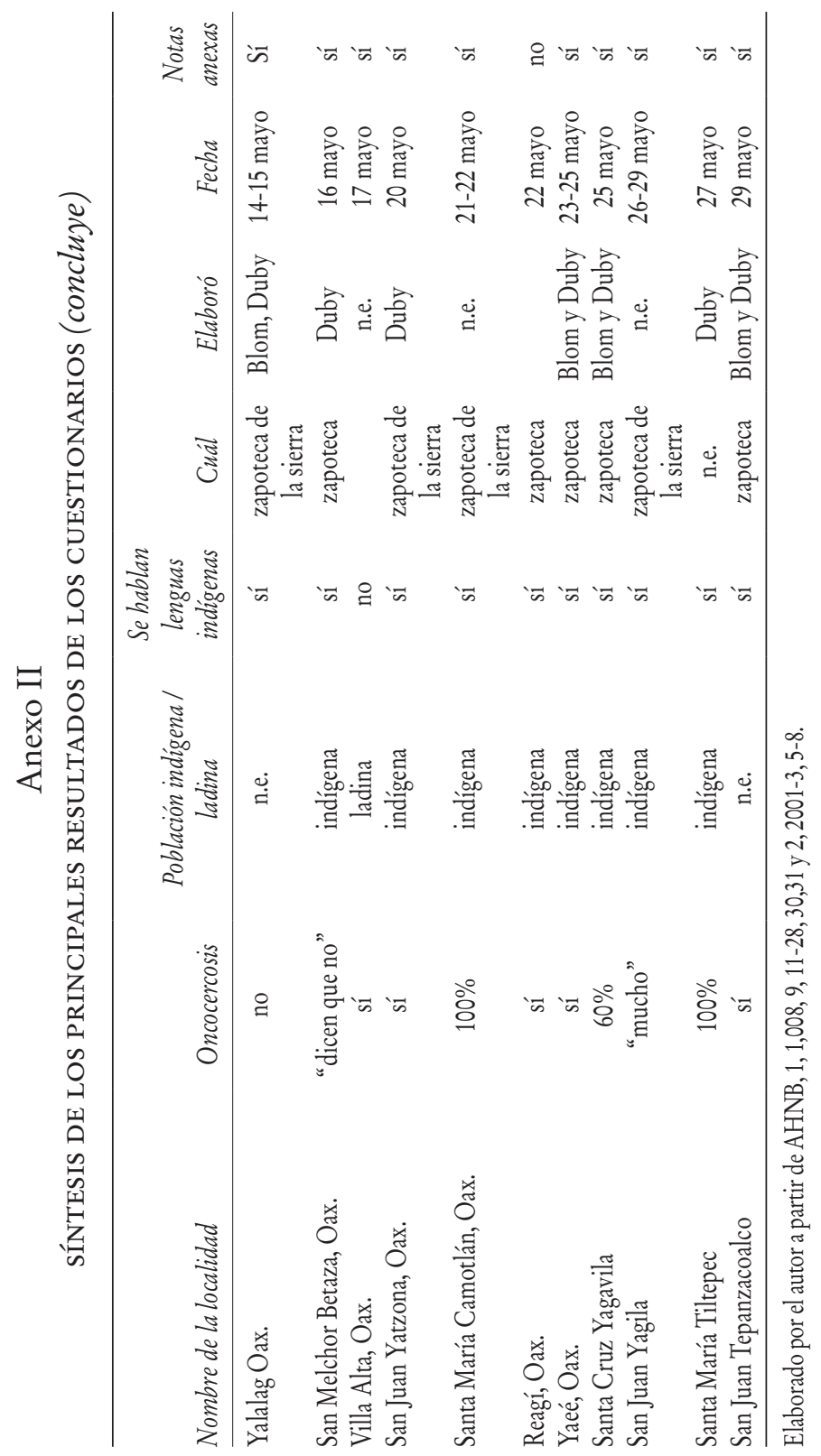

